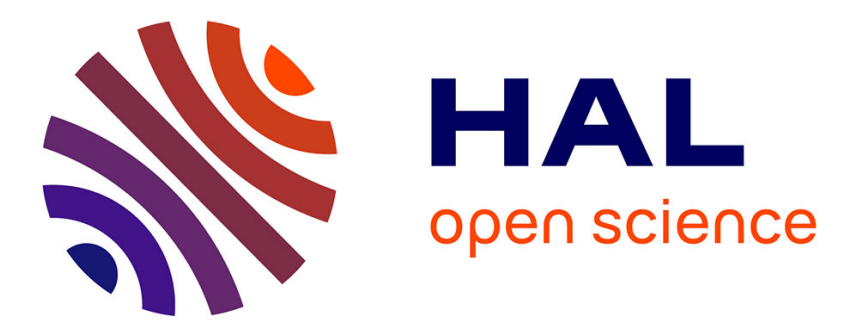

\title{
Locating Rockfalls Using Inter Station Ratios of Seismic Energy at Dolomieu Crater, Piton de la Fournaise Volcano
}

J. Kuehnert, A. Mangeney, Y. Capdeville, J. P. Vilotte, E. Stutzmann, E. Chaljub, E. Aissaoui, P. Boissier, C. Brunet, P. Kowalski, et al.

\section{To cite this version:}

J. Kuehnert, A. Mangeney, Y. Capdeville, J. P. Vilotte, E. Stutzmann, et al.. Locating Rockfalls Using Inter Station Ratios of Seismic Energy at Dolomieu Crater, Piton de la Fournaise Volcano. Journal of Geophysical Research: Earth Surface, 2021, 126, 10.1029/2020JF005715 . insu-03590066

\section{HAL Id: insu-03590066 https://hal-insu.archives-ouvertes.fr/insu-03590066}

Submitted on 3 Mar 2022

HAL is a multi-disciplinary open access archive for the deposit and dissemination of scientific research documents, whether they are published or not. The documents may come from teaching and research institutions in France or abroad, or from public or private research centers.
L'archive ouverte pluridisciplinaire HAL, est destinée au dépôt et à la diffusion de documents scientifiques de niveau recherche, publiés ou non, émanant des établissements d'enseignement et de recherche français ou étrangers, des laboratoires publics ou privés.

$$
\text { Copyright }
$$




\section{JGR Earth Surface}

\section{RESEARCH ARTICLE \\ 10.1029/2020JF005715 \\ Locating Rockfalls Using Inter-Station Ratios of Seismic Energy at Dolomieu Crater, Piton de la Fournaise Volcano}

Key Points:

- Rockfalls are located using generated seismic signals at high frequencies for highly resolved spatial and temporal tracking

- Rockfall location is improved using the signature of surface topography on seismic signals simulated with the three-dimensional Spectral Element Method

- By accounting for topography, all signal components can be used, critical in the case of sparse station networks or noise

Supporting Information:

Supporting Information may be found in the online version of this article.

Correspondence to:

J. Kuehnert,

kuehnert@ipgp.fr

Citation:

Kuehnert, J., Mangeney, A., Capdeville, Y., Vilotte, J. P., Stutzmann, E., Chaljub, E., et al. (2021). Locating rockfalls using inter-station ratios of seismic energy at Dolomieu crater, Piton de la Fournaise volcano. Journal of Geophysical Research: Earth Surface, 126, e2020JF005715. https://doi. org/10.1029/2020JF005715

Received 2 JUN 2020

Accepted 14 MAR 2021

(C) 2021. American Geophysical Union. All Rights Reserved.

\author{
J. Kuehnert ${ }^{1}$ (), A. Mangeney ${ }^{1}$ (), Y. Capdeville ${ }^{2}$ () J. J. P. Vilotte ${ }^{1}$, E. Stutzmann ${ }^{1}$ (), E. Chaljub ${ }^{3}$, \\ E. Aissaoui ${ }^{1}$, P. Boissier ${ }^{1,4}$ (I) C. Brunet ${ }^{1,4}$, P. Kowalski ${ }^{1,4}$ (I) and F. Lauret ${ }^{1,4}$ \\ ${ }^{1}$ Université de Paris, Institut de Physique du Globe de Paris, CNRS, Paris, France, ${ }^{2}$ Laboratoire de Planétologie et \\ Géodynamique, UMR CNRS 6112, Université de Nantes, Nantes, France, ${ }^{3}$ Université Grenoble Alpes, Université Savoie \\ Mont Blanc, CNRS, IRD, IFSTTAR, ISTerre, Grenoble, France, ${ }^{4}$ Observatoire Volcanologique du Piton de la Fournaise, \\ Institut de Physique du Globe de Paris, CNRS, UMS 3454, UMR 7154, La Plaine des Cafres, France
}

\begin{abstract}
Rockfalls generate seismic signals that can be used to detect and monitor rockfall activity. Event locations can be estimated on the basis of arrival times, amplitudes, or polarization of these seismic signals. However, surface topography variations can significantly influence seismic wave propagation and hence compromise results. Here, we specifically use the signature of topography on the seismic signal to better constrain the source location. Seismic impulse responses are predicted using Spectral Element based simulation of three-dimensional wave propagation in realistic geological media. Subsequently, rockfalls are located by minimizing the misfit between simulated and observed inter-station energy ratios. The method is tested on rockfalls at Dolomieu crater, Piton de la Fournaise volcano, Reunion Island. Both single boulder impacts and distributed granular flows are successfully located, tracking the complete rockfall trajectories by analyzing the signals in sliding time windows. Results from the highest frequency band (here 13-17 Hz) yield the best spatial resolution, making it possible to distinguish detachment positions less than $100 \mathrm{~m}$ apart. By taking into account surface topography, both vertical and horizontal signal components can be used. Limitations and the noise robustness of the location method are assessed using synthetic signals. Precise representation of the topography controls the location resolution, which is not significantly affected by the assumed impact direction. Tests on the network geometry reveal best resolution when the seismometers triangulate the source. We conclude that this method can improve the monitoring of rockfall activity in real time once a simulated database for the region of interest is created.
\end{abstract}

\section{Introduction}

Seismology is increasingly used to study and monitor dynamic processes at the interface between the Earth and its fluid envelopes, a field often more specifically referred as environmental seismology (K. E. Allstadt et al., 2018; Larose et al., 2015). Surface processes can include natural phenomena such as storms (e.g., Ebeling \& Stein, 2011; Stutzmann et al., 2012), glaciers (e.g., Podolskiy \& Walter, 2016; Sergeant et al., 2016, 2019; Tsai et al., 2008), rivers (e.g., Gimbert et al., 2014), debris flow (e.g., Burtin et al., 2009), snow avalanches (e.g., Leprettre \& Navarre, 1998; Norris, 1994; Suriñach et al., 2000, 2001) as well as landslides and rockfalls (e.g., K. Allstadt, 2013; Bottelin et al., 2014; Favreau et al., 2010; Hibert et al., 2011; Suriñach et al., 2005; Vouillamoz et al., 2018).

In the context of landslides (used here as the most general term for gravitational mass movements), seismic signals can be used to identify hazards. Growing networks of seismic stations offer the opportunity to continuously monitor large regions of interest. Landslide events can be detected, characterized, and located using the seismic signals they generate (e.g., Hibert et al., 2014; E.-J. Lee et al., 2019; Provost et al., 2017; Suriñach et al., 2005). This helps in creating catalogs of landslides that allow statistical analysis of their spatial and temporal activity and estimation of their probability of occurrence. In this way, triggering mechanisms can be studied by correlating landslide catalogs with meteorological data (Burtin et al., 2009; Durand et al., 2018; Helmstetter \& Garambois, 2010) or with volcanic seismicity data (Durand et al., 2018; Hibert, Mangeney, et al., 2017). On volcanoes, rockfall locations can provide insight into volcano summit deformation (Durand et al., 2018), and seismic signals are also used to monitor other processes such as lahars (e.g., Coviello et al., 2018; Vázquez et al., 2016; Zobin, 2012; Zobin et al., 2009) as well as magma migration (e.g., Duputel et al., 2019; Lengliné et al., 2016; Taisne et al., 2011). 
Several methods for locating landslides from seismic signals have been proposed and can be divided into two main groups. In the first group, the source location is inferred geometrically by pointing to it from several stations and determining the intersection. This can be done by polarization analysis with three-component seismometers (Vilajosana et al., 2008) or by array analysis methods that estimate the apparent slowness vector (Almendros et al., 2002). In the second group, seismic signal properties are back-projected, optimizing correlation between multiple stations. The back-projection relies either on the decay of amplitudes with distance, using methods such as amplitude source location (ASL, e.g., Battaglia \& Aki, 2003; Battaglia et al., 2005; Morioka et al., 2017; Pérez-Guillén et al., 2019; Walsh et al., 2017; Walsh et al., 2020; Walter et al., 2017) and seismic intensity ratios (e.g., Taisne et al., 2011), or on travel time differences between stations pairs, using cross-correlation of signal envelopes (Bottelin et al., 2014; Burtin et al., 2009; Dietze et al., 2017; Lacroix \& Helmstetter, 2011; Yamada et al., 2012) or inversion of first arrival times (Fuchs et al., 2018; Gracchi et al., 2017; Hibert et al., 2014). Li et al. (2020) reviews recent advances of back-projection methods to locate seismic sources, including wave field migration, waveform inversion, semblance and template matching.

As landslides predominantly occur in mountainous regions, generated seismic waves are prone to interact with rough surface topography variations. The influence of topography on seismic wave propagation has long been a subject of study (Geli et al., 1988). Topography can affect the wave path, wave polarization (e.g., Métaxian et al., 2009; Ripperger et al., 2003) and seismic amplitudes (e.g., S.-J. Lee et al., 2009; Maufroy et al., 2015). If not taken into account correctly, topographic effects compromise location methods and decrease their accuracy.

Assuming elongated wave paths along the topography, back-projection methods can take topography into account by adjusting source-receiver distances and thus travel times. This was done for example by Hibert et al. (2014) to locate rockfalls at Dolomieu crater, Reunion Island, and by Levy et al. (2015) to locate granular flows at Soufrière Hills volcano, Montserrat. However, adjusting the source-receiver distance does not account for diffraction or scattering during the propagation of the seismic wave along the topography.

In the following, we propose a new location method that accounts for the cumulative effect of the topography on the recorded signal. The method is based on the work of Kuehnert et al. (2020), in which topography effects on the seismic wave field were investigated using the three-dimensional (3D) Spectral Element Method (SEM, e.g., Chaljub et al., 2007; Komatitsch \& Vilotte, 1998) in combination with a realistic geological domain. By calculating seismic energy ratios between stations pairs and hence removing the signature of the seismic source, they concluded that observed energy ratios from recorded rockfall signals can be reproduced when topography is considered in the simulations and site effects are removed from the observations. This is used here for locating seismic sources by constructing a database of simulated energy ratios from a grid of potential source positions with $10 \mathrm{~m}$ spacing which are then compared to the observed energy ratios after site effect correction using spectral amplification functions estimated from volcano-tectonic (VT) events.

The method is tested on seismic signals generated by rockfalls at Piton de la Fournaise volcano, Reunion Island. After analyzing one rockfall in detail to tune the method for best resolution, a variety of diverse rockfall events are located. As the method assumes single sources, its performance for largely distributed sources such as granular flows is evaluated. Finally, to investigate the limitations of the method, synthetic rockfall signals are constructed from single as well as multiple source positions. A resolution proxy is defined to test the station coverage and identify network geometries with enhanced resolution. Furthermore, the sensitivity of the locating method to the ambient noise level as well as to the underlying model assumptions such as the topography resolution and the source impact direction is assessed.

\section{Rockfall Seismic Signals at Dolomieu Crater, Reunion Island}

The study site is located on Piton de la Fournaise volcano, Reunion Island, shown in Figure 1a. Rockfalls occur frequently on the unstable flanks of Dolomieu crater, which was formed during the caldera collapse in 2007 (Michon et al., 2007). The volcano is monitored by the Observatoire Volcanologique du Piton de la Fournaise (OVPF). The instrumentation, which includes both seismic stations and cameras, allows rockfall analysis by correlating recorded seismic signals with video recordings. For the present study, four stations around the Dolomieu crater with a sampling frequency of $100 \mathrm{~Hz}$ are used, namely the three-component 

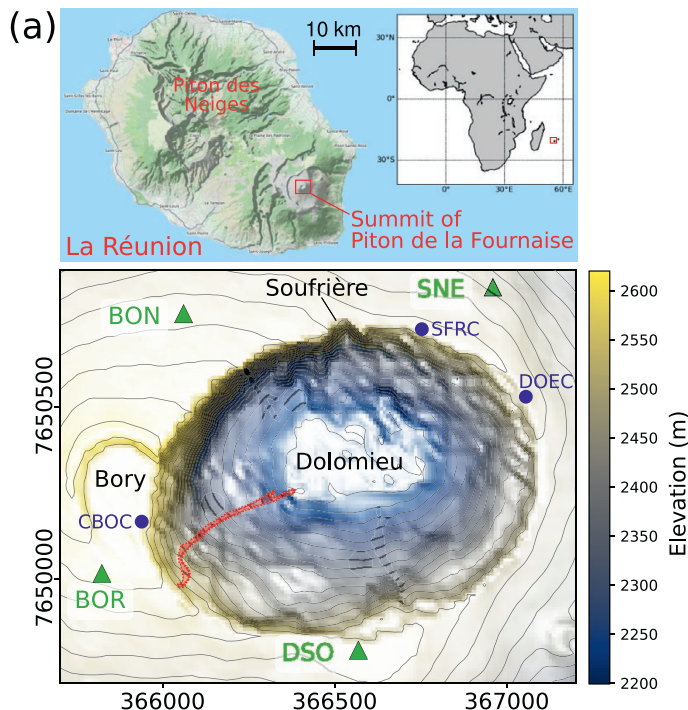

(b)

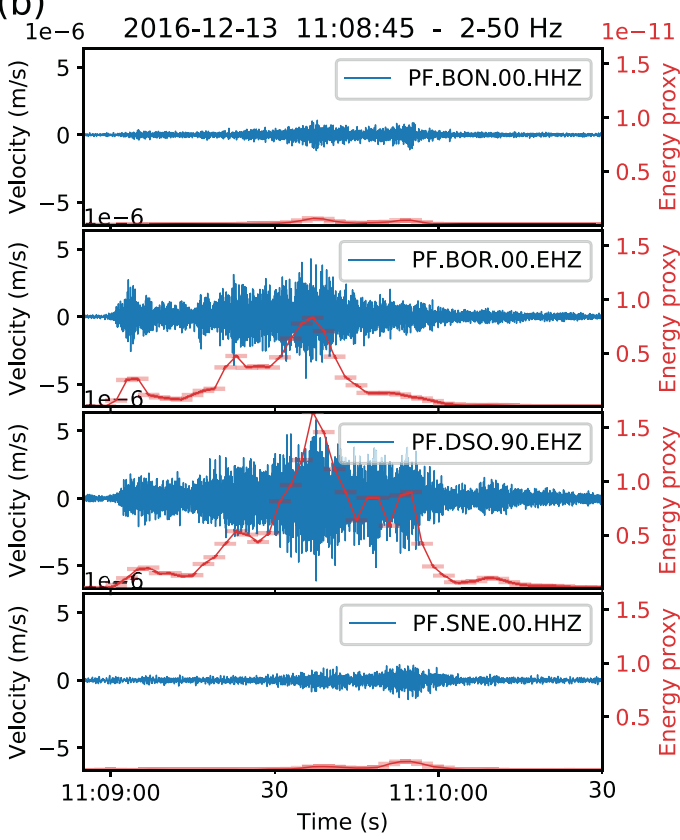

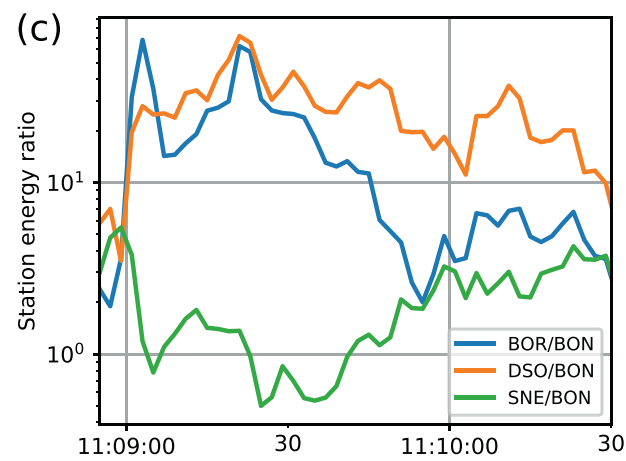

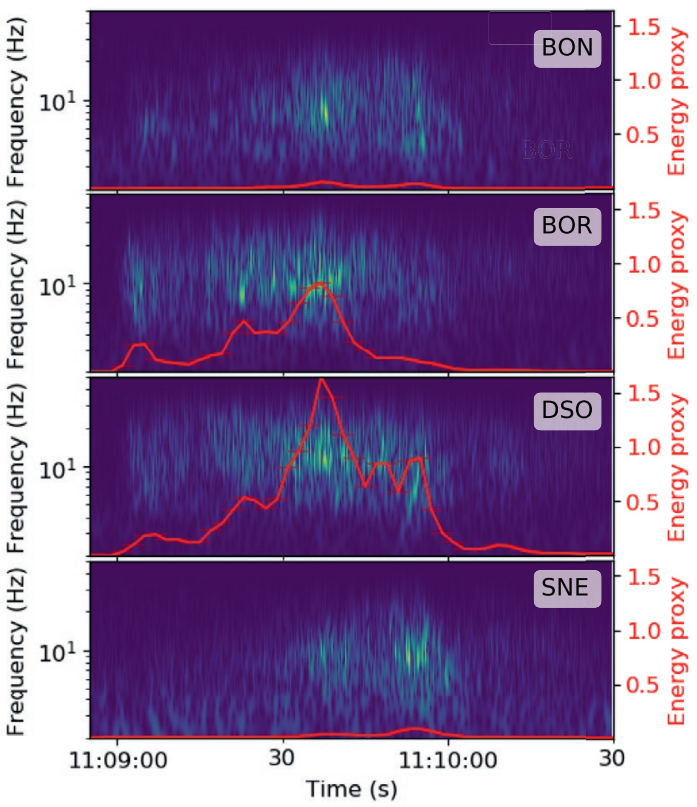

Figure 1. (a) Map of Reunion Island (top) and hillshaded elevation map of Dolomieu crater on Piton de la Fournaise volcano (bottom). The smaller Bory and Soufrière craters are located west and north of Dolomieu crater, respectively. Seismic stations are marked by green triangles and cameras by blue dots. The red zone marks a rockfall trajectory estimated from the video. (b) Seismograms (left) and corresponding spectrograms (right) of vertical velocity generated by a rockfall on December 13, 2016, corresponding to the red trajectory indicated in (a). The signals were recorded at the four seismic stations surrounding Dolomieu crater. The red curves are the seismic energy proxy $E_{i z}$ (according to Equation 1), calculated from a sliding time window in steps of $2 \mathrm{~s}$ and of width $d=4 \mathrm{~s}$. Ambient seismic noise can only be detected in the spectrogram at furthest station SNE below $3 \mathrm{~Hz}$. (c) Inter-station energy ratios from vertical ground velocity. The beginning of the seismic signal emitted by the rockfall is marked by an abrupt change of the ratios.

stations BON, BOR, and SNE and the vertical component station DSO. BON and SNE are broadband (i.e., corner frequency $\leq 0.1 \mathrm{~Hz}$ ), BOR and DSO are short-period (i.e., corner frequency $>0.1 \mathrm{~Hz}$ ) stations. The three cameras CBOC, DOEC, and SFRC are located on the summit of Piton de la Fournaise, look into the Dolomieu crater and continuously sample two images per second. The supporting information of this article provides the seismograms and the videos of all analyzed rockfalls. To evaluate the results of the present location method, rockfall trajectories are manually estimated from the videos by determining landmarks visible on both the videos and the available Digital Elevation Model (DEM) of $10 \mathrm{~m}$ resolution. This way, 
the trajectory of a rockfall on December 13, 2016, is reconstructed and marked in red in Figure 1a. An uncertainty of $\pm 50 \mathrm{~m}$ is assumed.

The recorded ground velocity generated by this rockfall on the southwestern crater wall is shown in Figure 1b. The most abrupt signals are observed at BOR and DSO, the two closest stations, whereas the signals at stations BON and SNE at larger distances slowly rise in amplitude. The temporal evolution of the recorded signals can be characterized by a proxy of the seismic energy $E_{i j}$ measured at each station $i$ and component $j$ that we define as the square of the recorded ground velocity $v_{i j}^{2}(t)$, integrated over a sliding window of width $d$ :

$$
E_{i j}=\int_{d} v_{i j}^{2}(t) \mathrm{d} t
$$

Energy proxies $E_{i z}$, calculated from vertical component $j=z$, are shown in Figure $1 \mathrm{~b}$. Their inter-station ratios are shown in Figure 1c, where BON is chosen as the reference station. The beginning of the seismic signal generated by the rockfall is marked by an abrupt increase of the ratios BOR/BON and DSO/BON, whereas the ratio SNE/BON decreases. Subsequently, the ratios evolve differently as the rockfall moves toward the bottom of the crater.

As the seismic source is identical for all stations, the temporal evolution of energy ratios is caused by the wave propagation path. First of all, as the source position moves, the source-receiver distances vary, which modifies the amplitude of the signals because of geometric spreading and attenuation. Moreover, soil heterogeneities and topography can affect the wave propagation between the source and the receiver. By modeling the influence of the topography on the energy ratios through direct numerical wave simulation and by taking into account local heterogeneities using empirical site amplification factors, the present study aims to locate rockfalls with high spatial and temporal resolutions.

\section{Methodology}

The proposed methodology for estimating rockfall locations uses energy ratios between stations to predict source positions. The ratios characterize the path effects, while the energy of the source itself can be ignored. This was used for example by Taisne et al. (2011) to map magma propagation. Here we use this strategy to compare the observed energy ratios with simulated ones, which was shown by Kuehnert et al. (2020) to be possible considering the topography. Instead of using spectral ratios at single frequencies, we average the energy ratios within frequency bands of $4 \mathrm{~Hz}$. This makes the method more robust to fluctuations in spectral values. In order to explore all potential rockfall sources, reciprocal simulations are carried out, where the synthetic source is placed at the position of the seismometer and the wave field is recorded over the entire crater area. A grid search is then performed to find the source positions that best fit the observed energy ratios.

\subsection{SEM Simulations}

The propagation of the seismic wave field is simulated using the 3D SEM (e.g., Chaljub et al., 2007; Komatitsch \& Vilotte, 1998) in a numerical domain of dimensions $x=2,100 \mathrm{~m}$ (easting), $y=1,800 \mathrm{~m}$ (northing), and $z=600 \mathrm{~m}$ (depth) as shown in Figure 2a, identical to the domain of the simulations presented by Kuehnert et al. (2020).

The domain is meshed in the top $150 \mathrm{~m}$ with hexahedral elements of $10 \mathrm{~m}$ side length to correctly accommodate the surface topography of Dolomieu crater provided by a 2009 DEM of $10 \mathrm{~m}$ resolution. Further below in depth, the element size is increased to $30 \mathrm{~m}$ to reduce computational costs. A Zone of refinement connects the two different element sizes, while a smooth Buffer layer filters out short wavelength variations of the fine mesh that cannot be represented in the coarse mesh. A polynomial order of 5 is used in all elements. To simulate an unbounded domain, absorbing PMLs (Perfectly Matched Layers, e.g., Festa \& Vilotte, 2005) of $160 \mathrm{~m}$ thickness are attached on the sides and the bottom of the domain. 


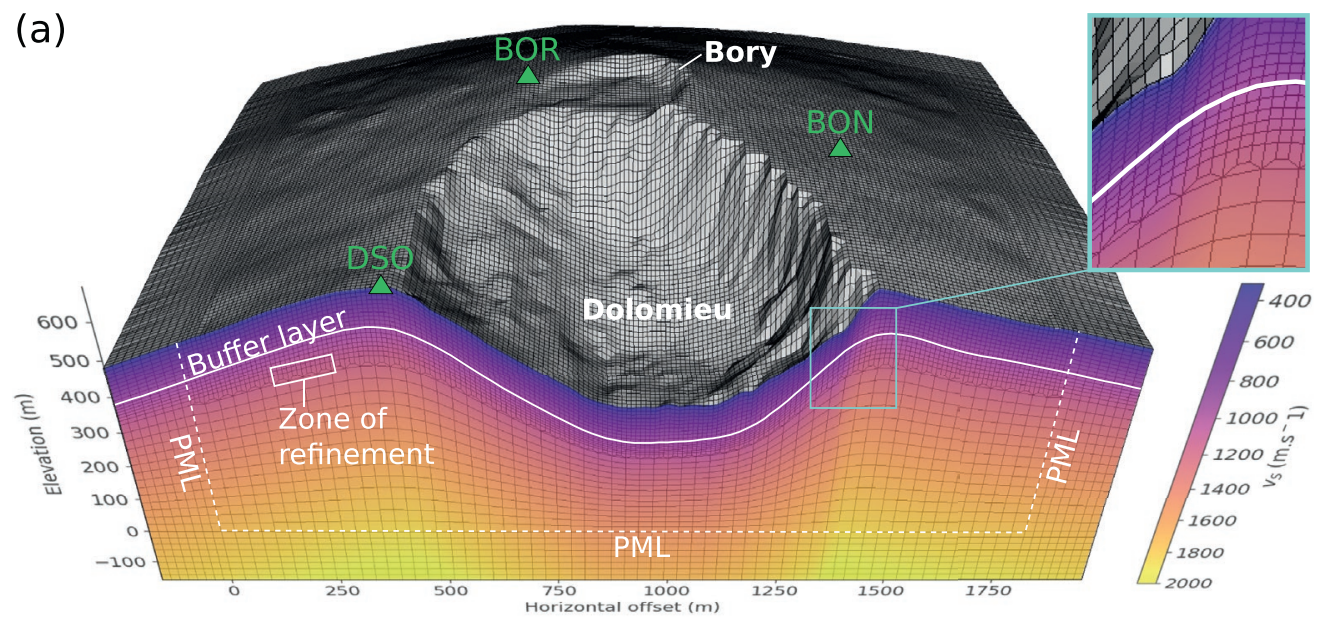

(b) Velocity-depth profile

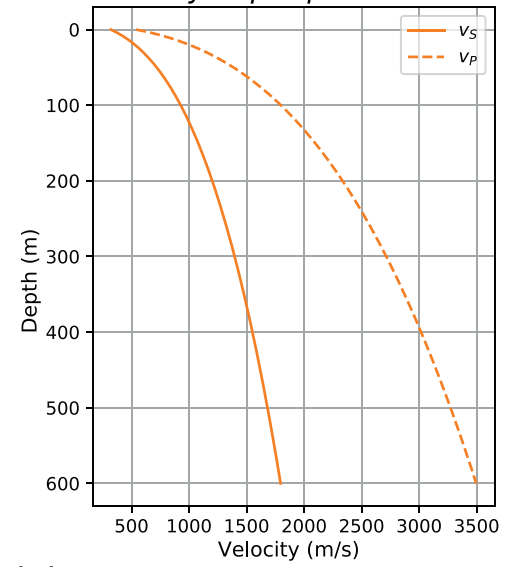

(c) Source-time function
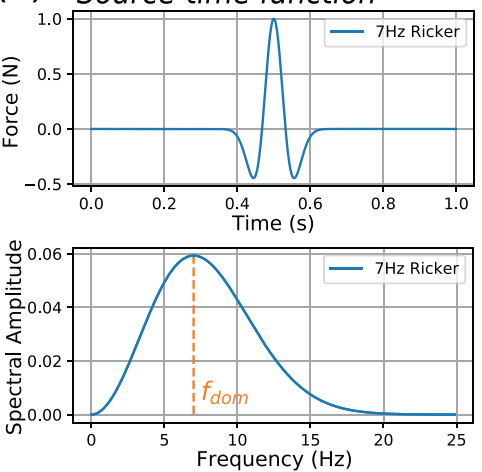

(d)

BOR

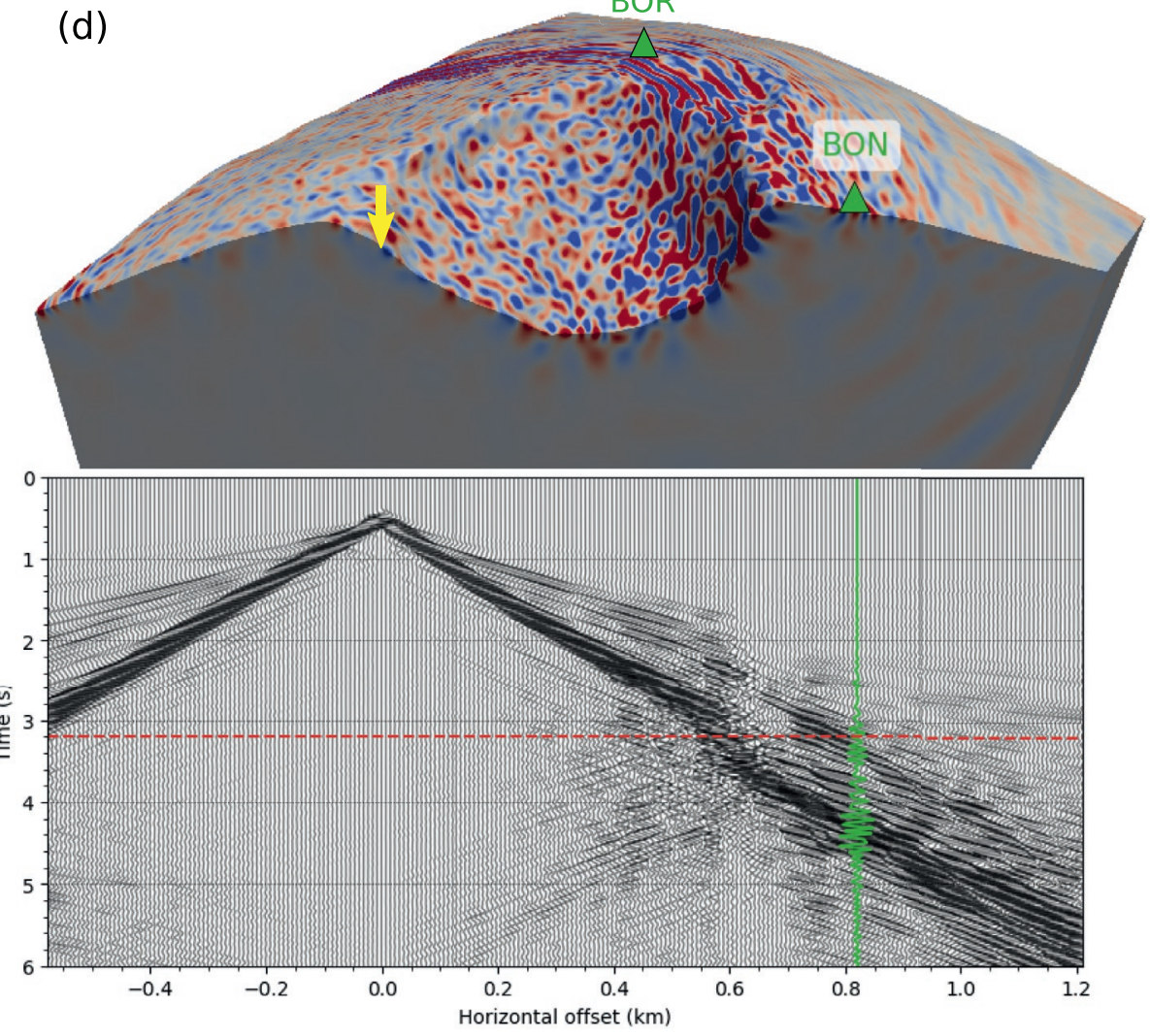

Figure 2. (a) Cross-section through the meshed domain with $10 \mathrm{~m}$ resolution surface topography from Dolomieu crater. The color map depicts the seismic velocity model. The elements have a side lengths of $10 \mathrm{~m}$ in the top $150 \mathrm{~m}$, increasing to $30 \mathrm{~m}$ below the Zone of refinement. Absorbing PMLs (Perfectly Matched Layers) of $160 \mathrm{~m}$ width are attached on the sides and bottom of the domain. (b) Generic velocity-depth profile for S-wave velocity $v_{S}$ (solid line) and P-wave velocity $v_{P}$ (dashed line) as proposed by Lesage et al. (2018) for the shallow structure of volcanoes. (c) Ricker wavelet of $7 \mathrm{~Hz}$ dominant frequency: Source-time function (top) and corresponding spectrum (below). (d) Simulation of the wave field (vertical velocity) from a vertical source on the southern crater wall (yellow arrow). On the top, a snapshot of the wave field is shown at time $t=3.2 \mathrm{~s}$, where positive amplitudes are denoted in red, negative in blue. The graph below shows the seismic traces recorded at the surface along the same cross-section. The green trace corresponds to the signal recorded at station BON.

The subsurface is parametrized using the generic velocity model proposed by Lesage et al. (2018) for the shallow structure of volcanoes. It is characterized by a velocity profile gradually increasing with depth as illustrated in Figure 2b. It is implemented on the 3D domain by laterally following the surface topography (i.e., each point at the surface is defined by depth $z=0 \mathrm{~m}$ ), deforming the horizontal layers of equal velocity. 

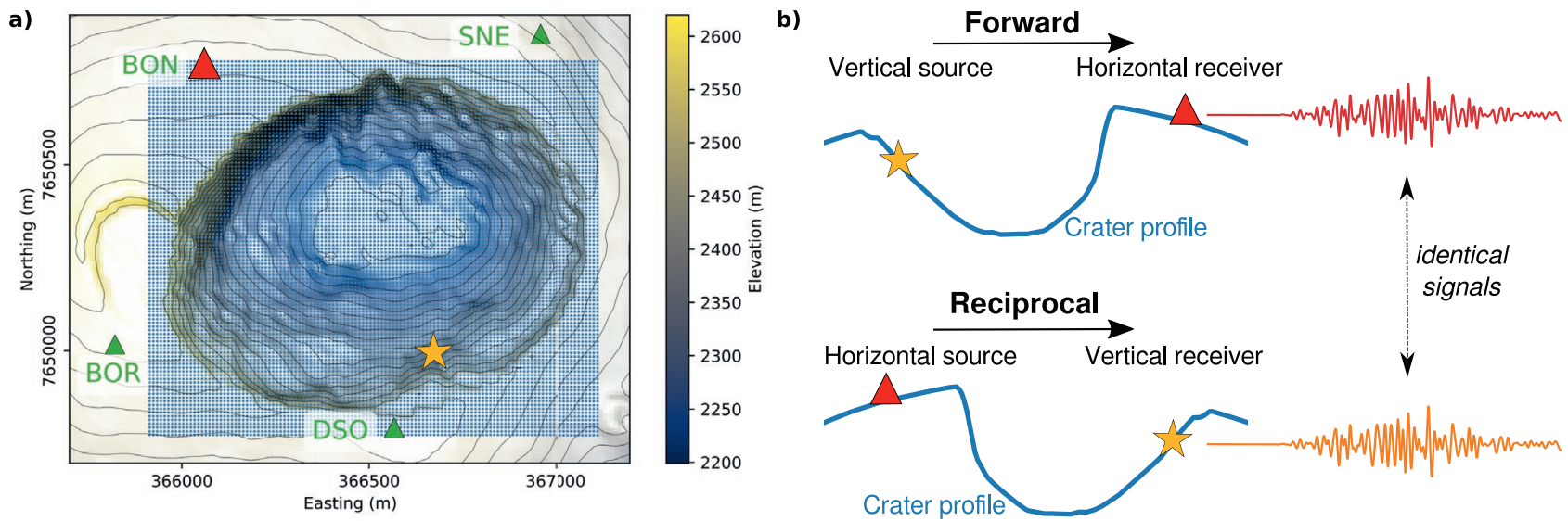

Figure 3. (a) Grid of receivers (in blue) for reciprocal simulations. The yellow star and red triangle are used to illustrate reciprocity in (b). The sampled area measures $1,200 \times 1,000 \mathrm{~m}$ (east $\times$ north). Sample spacing is $10 \mathrm{~m}$, resulting in $121 \times 101=12,221$ grid points. (b) Illustration of the principle of reciprocity. Top: Forward simulation where source (vertical) and receiver (horizontal) are placed at the position of the true source and the true receiver, respectively. Bottom: Reciprocal simulation, where a synthetic horizontal source replaces the true horizontal receiver and a synthetic vertical receiver replaces the true vertical source, resulting in identical synthetic seismograms.

Kuehnert et al. (2020) validated that this velocity model represents reasonably well the present study site at Piton de la Fournaise volcano by comparing simulated and recorded seismic signals of different rockfalls. The rock density is set to $\rho=2,000 \mathrm{~kg} \mathrm{~m}^{-3}$ and quality factors are set to $Q_{P}=80$ and $Q_{S}=50$ for P- and $\mathrm{S}$-wave velocity, respectively. These values are based on previous studies on Piton de la Fournaise and similar volcanoes (Battaglia \& Aki, 2003; Hibert et al., 2011; O'Brien \& Bean, 2009).

Seismic sources are represented by a point force and a Ricker wavelet of $7 \mathrm{~Hz}$ dominant frequency. This corresponds to a frequency range between 2 and $20 \mathrm{~Hz}$, in agreement with the predominantly observed seismic spectrum associated with rockfalls at the Dolomieu crater (see Figure 1b and e.g., Hibert et al., 2014). The source-time function as well as its spectral content is displayed in Figure 2c. A typical wave simulation is shown in Figure $2 \mathrm{~d}$ with a snapshot at time $t=3.2 \mathrm{~s}$ illustrating the wave field radiated by a vertical point source located at the southern crater wall (yellow arrow). It can be observed that the majority of seismic energy is located close to the surface as a result of the shallow low seismic velocity. The surface topography causes a highly scattered wave field. Synthetic seismograms recorded at the surface along the cross-section are shown in a time-offset representation. The wave field originates at the source location ( $0 \mathrm{~km}$ offset) and travels outwards in all directions. Wave scattering caused by the topography is detectable here, especially close to the crater rim at around $0.6 \mathrm{~km}$ offset with reflections back-propagating toward the bottom of the crater.

Concerning computational efforts, it takes a CPU time of around 10,000 CPU hours (10 cores per CPU) for one simulation on the presented domain (i.e., duration: 6 s, number of elements: 915,704, number of GLL points: 6, max. frequency: Approx. $20 \mathrm{~Hz}$, min. velocity: $320 \mathrm{~ms}^{-1}$ ). We run the simulations in parallel on 200 CPUs, leading to 2.3 days per simulation.

To efficiently explore different potential positions of the rockfall source without performing a simulation for each of them, the reciprocity principle is used (Aki \& Richards, 2002): The synthetic source is located at the station location and the wave field is recorded at the source location. Potential rockfall source positions are confined within a rectangular area at Dolomieu crater, shown in Figure 3a. The area is sampled by a grid of measurement points (in blue) with $10 \mathrm{~m}$ spacing.

The principle of reciprocity is illustrated in Figure 3b. It is shown that performing reciprocal simulations by interchanging source and receiver (and their corresponding directions) results in identical synthetic seismograms. In order to collect all necessary information, simulations for each component of all seismometers are carried out, that is, a point source is placed at the position of a given seismometer while the input force direction is aligned with the component of the seismometer. In total, 10 simulations are carried out: $3 \times 3$ simulations for the three-component seismometers BON, BOR, and SNE and one simulation for the 
single-component seismometer DSO. This is done for both the model with Dolomieu crater topography and for a model with a flat surface for comparison.

\subsection{Optimization Method for Source Location}

A source location probability estimate is associated with each point of the grid in Figure 3a by considering the inverse of the misfit between the synthetic energy ratio $E_{i j}^{\mathrm{simu}} / E_{\mathrm{ref}, j}^{\mathrm{simu}}$, computed when the source is actually located at that specific grid point, and the observed energy ratio $E_{i j, \mathrm{tw}}^{\mathrm{obs}} / E_{\mathrm{ref}, j, \mathrm{tw}}^{\mathrm{obs}}$. Here "ref" refers to the reference station, while $i$ designates the station and $j$ the component considered. Given that the rockfall source is moving, the observed energy ratio is evaluated over a time window "tw." The misfit $e_{\mathrm{tw}}$ for each time window is defined as follows:

$$
e_{\mathrm{tw}}=\frac{1}{N_{\mathrm{Sta}}} \sum_{i j}^{N_{\mathrm{Sta}}}\left|\log _{10}\left(\frac{E_{i j}^{\mathrm{simu}}}{E_{\mathrm{ref}, j}^{\mathrm{simu}}} \div \frac{E_{i j, \mathrm{tw}}^{\mathrm{obs}}}{E_{\mathrm{ref}, j, \mathrm{tw}}^{\mathrm{obs}}}\right)\right| \text {, }
$$

where $N_{\text {Sta }}$ is the number of station-channel pairs to be considered, with each component counted separately. Zero misfit is achieved when simulated and observed energy ratios are equal. Using the logarithm in Equation 2 distributes their relative values equally around zero. This, combined with the absolute value, ensures that the misfit estimation is not biased by the reference station. The probability of the source location is calculated by the inverse of misfit $e_{\mathrm{tw}}$ and scaled to a probability density function with relative values between 0 and 1 . Alternative formulas were investigated, for example the relative difference between simulated and observed energy ratios or approaches with conditional statements. However, the estimate in Equation 2 was evaluated to be the most appropriate for the location problem, notably because it results in spatially smooth varying probability values and because it is not biased toward the reference station.

In order to consider the frequency dependency of the energy ratios, location is carried out in different frequency bands, namely at 3-7, 8-12, and 13-17 Hz. This selection is defined to cover a large part of the available frequency content from the simulations and the observations. A bandwidth of $4 \mathrm{~Hz}$ is assumed to be narrow enough to respect the dispersive character of the energy ratios and broad enough to average over fluctuations of the spectral ratios. Noise levels at Dolomieu crater are very low at frequencies above $3 \mathrm{~Hz}$ and can be ignored in the tests. Tests of the location method with added synthetic withe noise are performed in Section 5.3 .

Selecting the width of time window "tw" over which the observed seismic energy is estimated requires special attention. On the one hand, the width has to be chosen as small as possible in order to sample the moving source. On the other hand, as the same time window is used for all stations, most of the seismic signal generated by a given rockfall source has to arrive at each of the stations within the time window. In order to respect both criteria, a window width of $4 \mathrm{~s}$ is defined, and confirmed by simulations to be an appropriate compromise.

To allow comparison between observed and simulated energy ratios, the recorded signals must first be corrected for local site amplification, not considered in the simulations. Therefore, site amplification functions were estimated for each station channel using thirty-six VT events that were centered around $2 \mathrm{~km}$ below Dolomieu crater. Station BON is used as the reference station given its low spectral amplitudes from VT recordings as well as low spectral $\mathrm{H} / \mathrm{V}$ noise ratios. The resulting site amplification functions are shown in Figure 4. The site effect correction is performed prior to locating by deconvoluting the recorded signals with the spectral amplification functions.

To test the influence of the above parameters and site effects on the location method, a hands-on Jupyter notebook (Kluyver et al., 2016) is published on https://github.com/Jubeku/RF_localization (Kuehnert et al., 2019).

\subsection{The Influence of Topography on Inter-Station Energy Ratios}

The relative amplitudes recorded at various stations can be influenced by the topography (e.g., Kuehnert et al., 2020), thus modifying the energy ratios in Equation 2. Having built databases of the simulated 


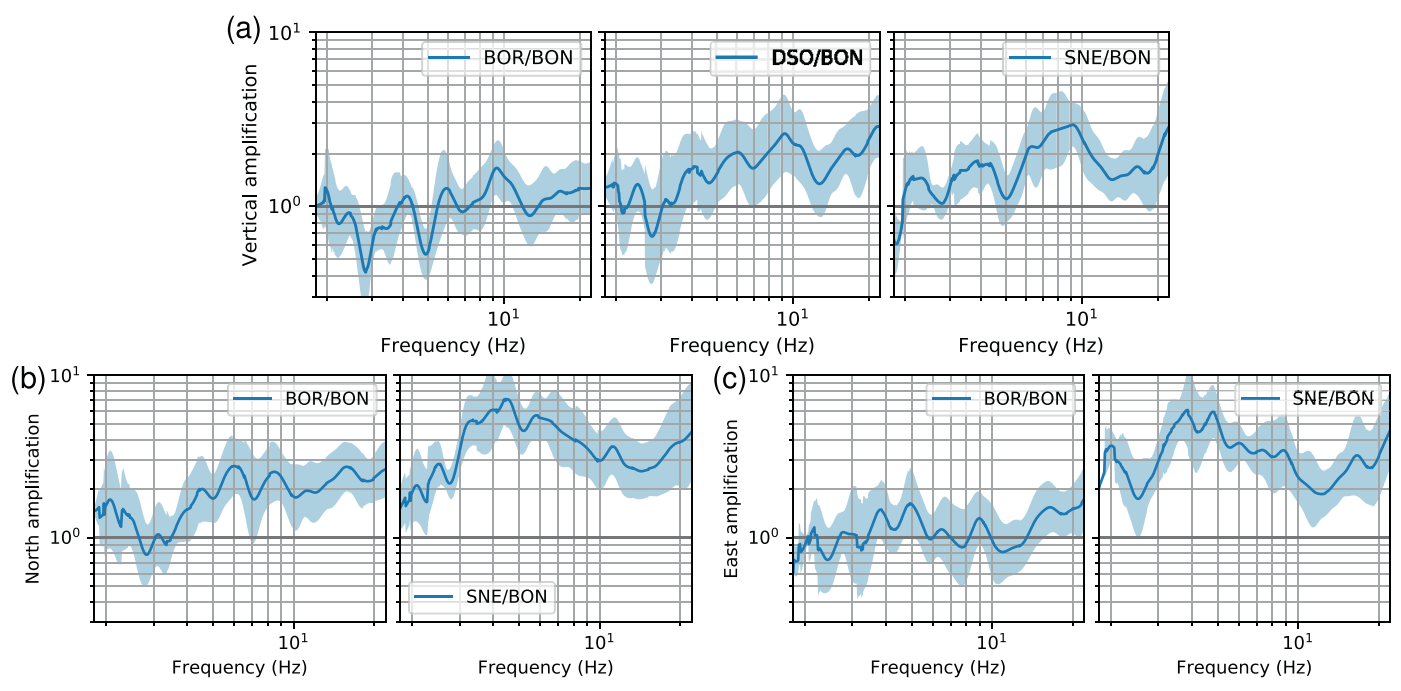

Figure 4. Spectral amplification functions estimated from volcano-tectonic (VT) events relative to reference station BON. Amplification is calculated from smoothed spectral ground velocity recorded by: (a) vertical components, (b) north components, and (c) east components. Smoothing is performed as proposed by Konno and Ohmachi (1998). The blue-shaded area indicates the standard deviation of the amplification as calculated from all VTs. Figure adapted from Kuehnert et al. (2020).

energies $E_{i j}^{\text {simu }}$ for a domain with a flat surface and a domain with topography, we can gain a first insight into the influence of topography by comparing the resulting synthetic energy ratios.

This is done in Figure 5, where the energy ratio between station pair BOR and BON at each grid point of potential source locations is shown for a flat surface (top) and for the Dolomieu topography (bottom). The energy ratios $E_{i j}^{\mathrm{simu}} / E_{\mathrm{ref}, j}^{\mathrm{simu}}$ are calculated respectively from all three components $j=Z, N, E$ and reference station $i=$ ref is chosen to be BON.
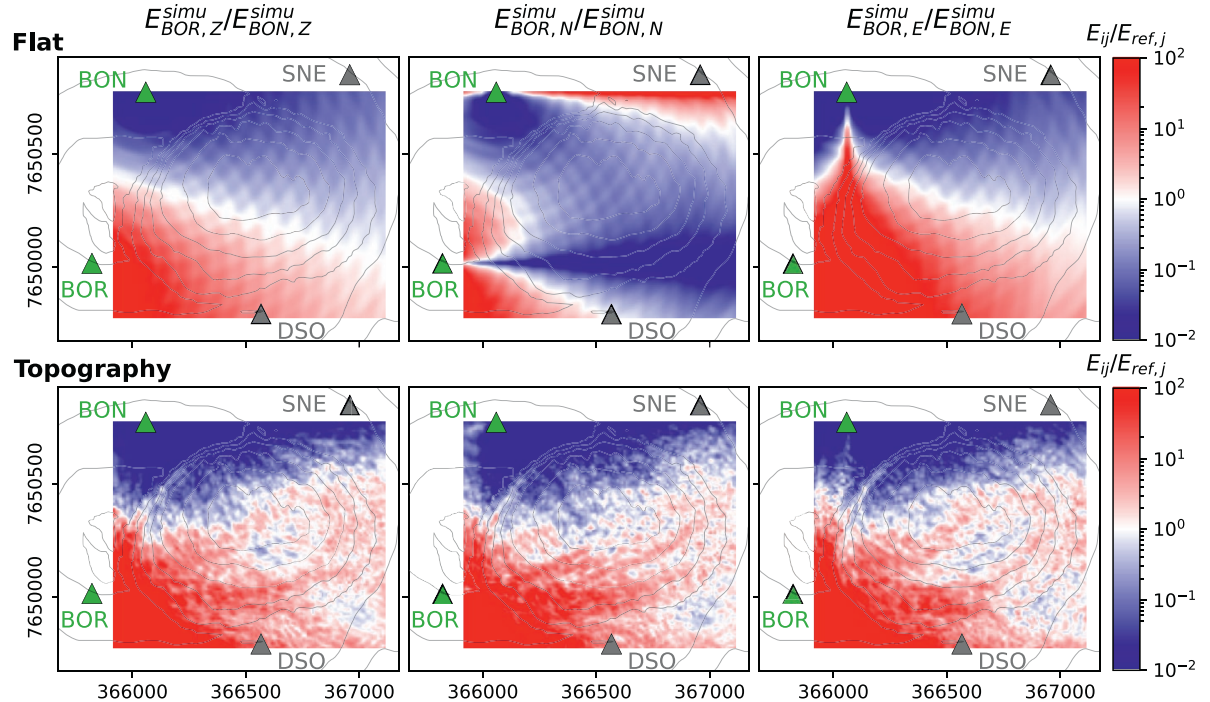

Figure 5. Seismic energy ratios between station pair BOR and BON (in green) from simulations on a domain with a flat surface (top) and a domain with topography (bottom). At each grid point (see Figure 3a), representing a potential source position, the ratio is computed from vertical component seismic energy $E_{i, Z}$ (left), north component seismic energy $E_{i, N}$ (middle), and east component seismic energy $E_{i, E}$ (right). Unfiltered synthetic seismograms were used for the calculation. 
For the domain with a flat free surface, when vertical signal component $j=Z$ is measured, we can observe a bipolar pattern of the energy ratios with values $>1$ toward station BOR and values $<1$ toward reference station BON, while unity is reached at equidistant positions between the station pair. Values are determined purely by the source receiver distances. The energy ratios from the horizontal signal components $i=N, E$ result in a more complicated spatial pattern. This is because the radiation pattern from the vertical source in the horizontal plane is not radially isotropic.

For the domain with surface topography, in the case of vertical component $i=Z$, the pattern of energy ratios becomes distorted because of the signature of the topography in the wave field. In general, a bipolar spatial distribution of the energy ratios persists, indicating that the decay of seismic amplitude remains influenced by the source-receiver distance. The pattern of energy ratios from the horizontal signal components $i=N, E$ is comparable to the vertical pattern, indicating that the wave propagation along the topography dominates over source-characteristic radiation patterns. This topographic path effect (e.g., Kuehnert et al., 2020; Kumagai et al., 2011) is similar to the distortion of radiation patterns by the scattering of the wave field by smallscale soil heterogeneities, validating the assumption of an isotropic radiation at high frequencies above around $5 \mathrm{~Hz}$ (e.g., Kumagai et al., 2010; Takemura et al., 2009). As a consequence, the presented method can be implemented independently of the source impact direction used in the simulations (here we have chosen a vertical surface traction), whereby both vertical and horizontal component signals can be used for location. We show here that leveraging horizontal component signals can improve the locating results. Typically, only vertical component signals are used in rockfall location methods, except for polarization approaches such as proposed by Vilajosana et al. (2008).

\section{Application to Rockfalls at Dolomieu Crater}

The proposed formalism to evaluate the relative probability of potential source locations on a predefined grid of positions is now applied to rockfall seismic signals recorded at Piton de la Fournaise volcano. After analyzing individual time windows, all probabilities derived from a sliding time window are combined in the attempt to reconstruct the full rockfall trajectory.

\subsection{Rockfall Location at Given Time Steps}

The location method is initially tested for a rockfall that occurred on December 13, 2016, corresponding to the event presented in Figure 1. The analysis is carried out at six different times (i) to (vi) as indicated on the seismogram in Figure 6. Above the seismogram, the whole trajectory is shown as well as camera snapshots of times (ii) to (v).

Time (i) is just before the start of the rockfall. Time (ii) is after the detachment, when movements can be detected on the video. At time (iii), the rockfall appears from behind a small valley at the top of the crater wall. Thereafter, the rockfall accelerates, which leads to stronger impacts and thus to the highest signal amplitudes. A total of three boulders are detected at time (iv) on their way down toward the crater bottom. At time (v), the third boulder arrives at the bottom. No movement is detected later on the video at time (vi). Nevertheless, it can be assumed that smaller granular material is still active on the flank, causing small amplitude seismic signals.

Rockfall location is performed here in the highest frequency band (13-17 Hz) with simulated energy ratios from the model with Dolomieu topography and using all available station-channel pairs, that is, $N_{\text {Sta }}=7$, adding up three station pairs for the vertical component and two station pairs each for the north and east component (DSO contains only the vertical component). Figure 7 shows the resulting source location probability maps at the six successive time steps (i) to (vi).

At time (i), most probable seismic sources are located at the center and the southeastern side of the crater. As the rockfall has not yet started at that time, the distribution must be related to ambient seismic noise. At time (ii), the source probability abruptly moves southwest, marking the beginning of the rockfall. The position of maximum probability is around $100 \mathrm{~m}$ from the estimated location of detachment. Then the area of probable source locations moves north at time (iii) with the most probable source location approaching the estimated rockfall position. The predicted source location continues to move along the rockfall trajectory at 


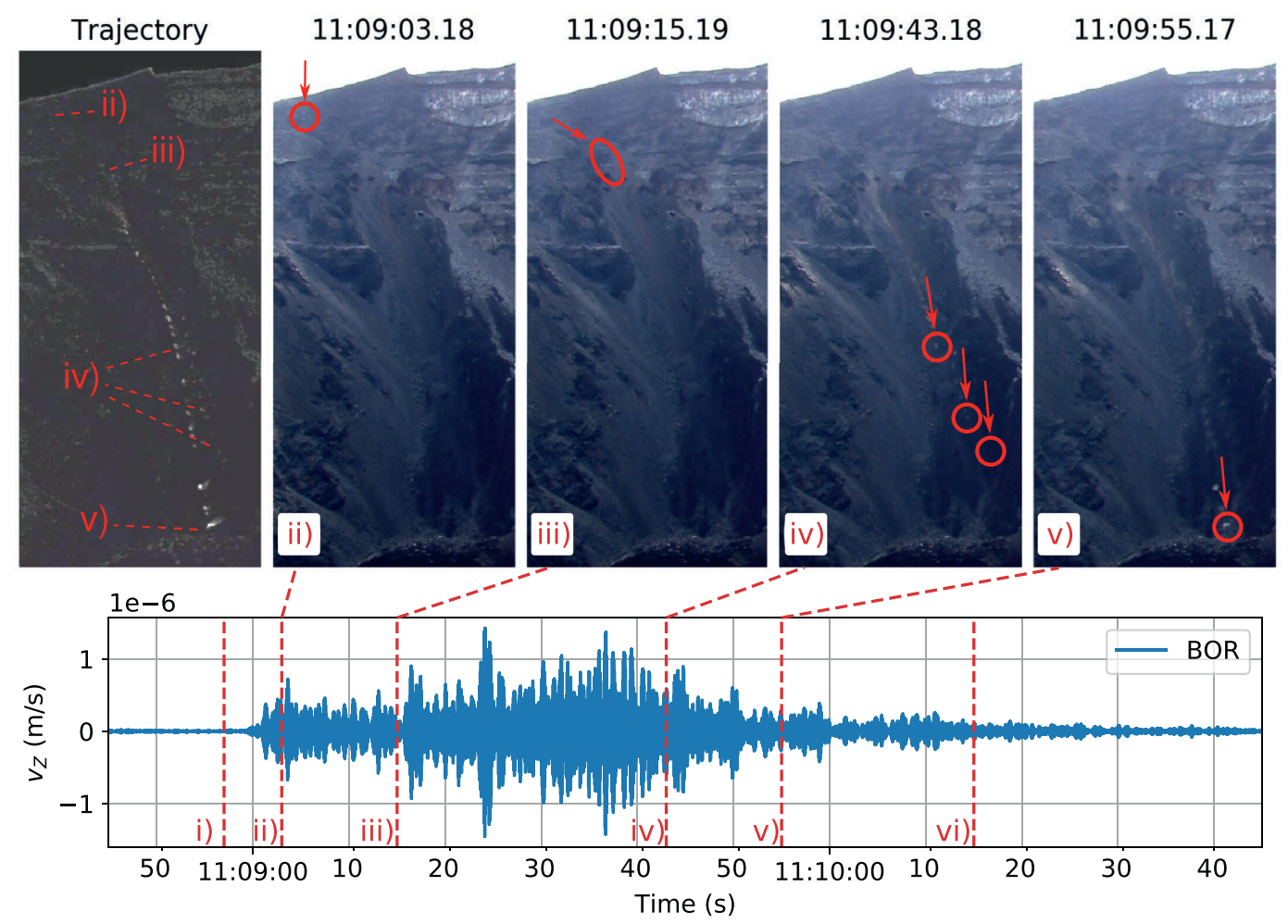

Figure 6. Camera images and seismic signal of a rockfall on December 13, 2016. Top: Images taken by camera DOEC The full rockfall trajectory on the left is reconstructed from differences between successive images. Toward the right, snapshots at times (ii) to (v) are displayed. Rockfall positions are indicated by red circles and the direction of movement by red arrows. Bottom: Vertical ground velocity $v_{Z}$ recorded at closest station BOR. Time steps (i) to (vi) are marked by red vertical dashed lines. Rockfall location is performed in time windows of $\pm 2 \mathrm{~s}$ around these time steps. The signal is bandpass filtered at $13-17 \mathrm{~Hz}$.
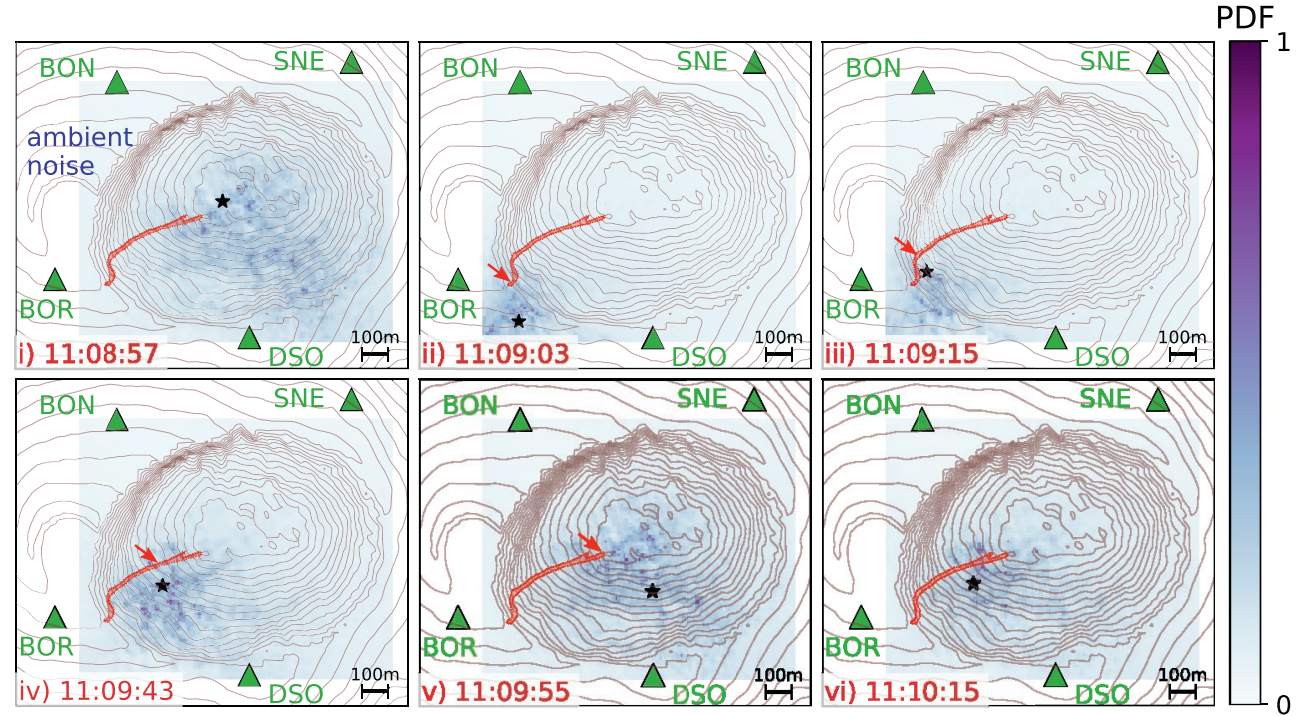

Figure 7. Location of seismic source at time steps (i) to (vi) as defined in Figure 6. The color-scale represents the source location probability. Black stars denote the position of maximum probability. Red shaded zone marks actual rockfall trajectory as estimated from the video and the red arrows approximate the current rockfall location. Locating is carried out in frequency band of $13-17 \mathrm{~Hz}$ using simulations from the model with Dolomieu topography. All stations and components are used, that is, $N_{\mathrm{Sta}}=7$. 
time (iv). At time (v), it arrives at the bottom of the crater. At this time, the position of maximum probability is at around $200 \mathrm{~m}$ from the estimated location. However, the distribution also shows densely populated high probabilities close to the estimated rockfall location. At time (vi), after the last boulder visible on the video has reached the crater floor, a zone of probable source positions remains in the lower part of the trajectory. This may be explained by the late movement of granular material that is not visible on the video.

The spatially scattered distribution of the predicted sources and the discrepancy between position of maximum probability and actual rockfall location imply a lack of resolution that can have several reasons. First, the source positions are somewhat ambiguous, that is, different locations can explain the observed seismic energy ratios equally well. Second, as observed on the video, the rockfall does not consist of a single boulder. The resulting seismic signal is hence a superposition of multiple sources shifted in time and space. Given that it is based on the assumption of a single source, the location method is flawed, a problem that will be studied in Section 5.1 using synthetic signals. The general southward shift of the predicted source locations compared to the true trajectory may also be caused by soil heterogeneities that affect seismic wave propagation and are not considered by either the simulations or the site impact correction. Another cause could be an inaccurate representation of the topography, which is possible since the DEM used here is from 2009, and the rockfall analyzed occurred in 2016.

\subsection{Spatio-Temporal Rockfall Evolution}

In order to reconstruct the full rockfall trajectory, the location method of Equation 2 is used with a sliding time window. Results from all time windows are combined at each potential source position by selecting the maximum probability over time. For each grid point, the minimum misfit $e$ between observed and simulated energy ratios is defined by

$$
e=\min _{\mathrm{tw}} e_{\mathrm{tw}}
$$

where $e_{\mathrm{tw}}$ is the misfit in each time window "tw" defined in Equation 2 . The maximum probability is the inverse of misfit $e$ and can be plotted for each spatial point. In this way, the temporal evolution of the rockfall trajectory can be displayed on a single graph.

Figure 8 a shows the resulting location map of the previously analyzed rockfall, using the same method configuration (i.e., at high-frequency $13-17 \mathrm{~Hz}$ and with all available station-channel pairs). Thanks to the color sequence, we can track how the rockfall moves from top to bottom of the crater over time in agreement with the observed rockfall trajectory from the video. Black stars denote the positions of maximum probability at time steps (ii) to (v), identical to those shown in Figure 7. Again, a general southward shift of around $100 \mathrm{~m}$ with respect to the video-estimated trajectory is observed.

Rockfall location is performed in different frequency bands. In the intermediate frequency band at 8-12 Hz, Figure $8 \mathrm{~b}$, the predicted source locations follow the movement of the actual trajectory and the positions of maximum probability are at distances comparable to those in Figure 8a. However, the resolution decreases as the spatial distribution of probable sources becomes much wider, covering large parts of the crater. The resolution is even worse in the lowest frequency band at 3-7 Hz, Figure 8c, where the general downward movement of the rockfall is hardly noticeable, with large discrepancies of the maximum probability positions in the time steps (ii) to (v). The observed decrease of resolution toward lower frequencies can be explained by the increase of the seismic wavelength. Assuming mainly fundamental-mode Rayleigh waves (Kuehnert et al., 2020), the wavelength for the velocity model used here increases from $26 \mathrm{~m}$ at $15 \mathrm{~Hz}$ by a factor of 1.7-44 $\mathrm{m}$ at $10 \mathrm{~Hz}$ and by a factor of 4.5-116 $\mathrm{m}$ at $5 \mathrm{~Hz}$; resolution can be expected to decrease accordingly.

A reduction in location error when higher frequencies are used in the location process is also reported by Lacroix and Helmstetter (2011). When analyzing single-impact signals with frequency contents up to $30 \mathrm{~Hz}$, they achieve locating accuracies of $50 \mathrm{~m}$ using beamforming and a priori measured seismic velocities. Similarly, when analyzing single impacts and frequency contents of 5-25 Hz, Dietze et al. (2017) achieves average location accuracies of $81 \mathrm{~m}$, comparing the results of back-projecting seismic envelopes with those of terrestrial laser scanning-based measurements. For continuous and distributed sources, the reported 
(a) 13-17 Hz - ENZ

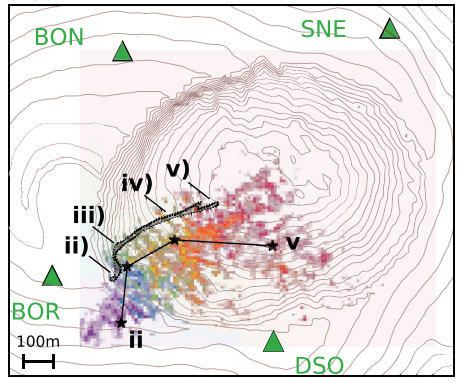

(d) 13-17 Hz - ENZ - uncorrected

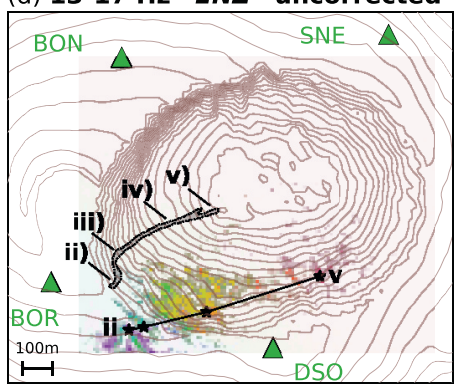

(b) 8-12 Hz - ENZ

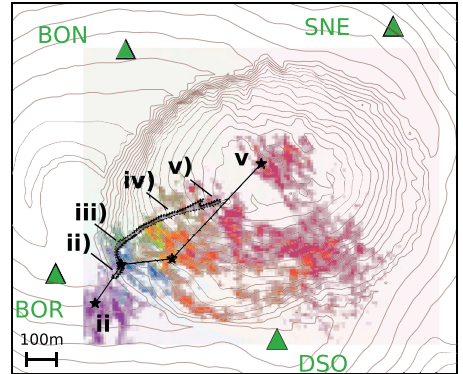

(e) 13-17 Hz - Z

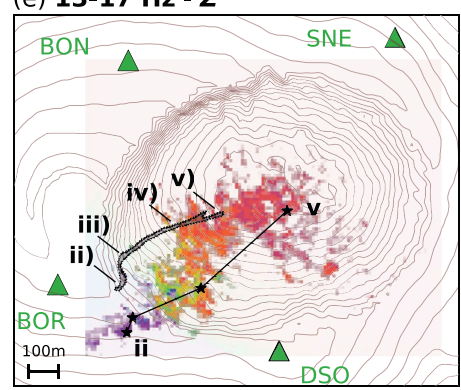

$\longmapsto$

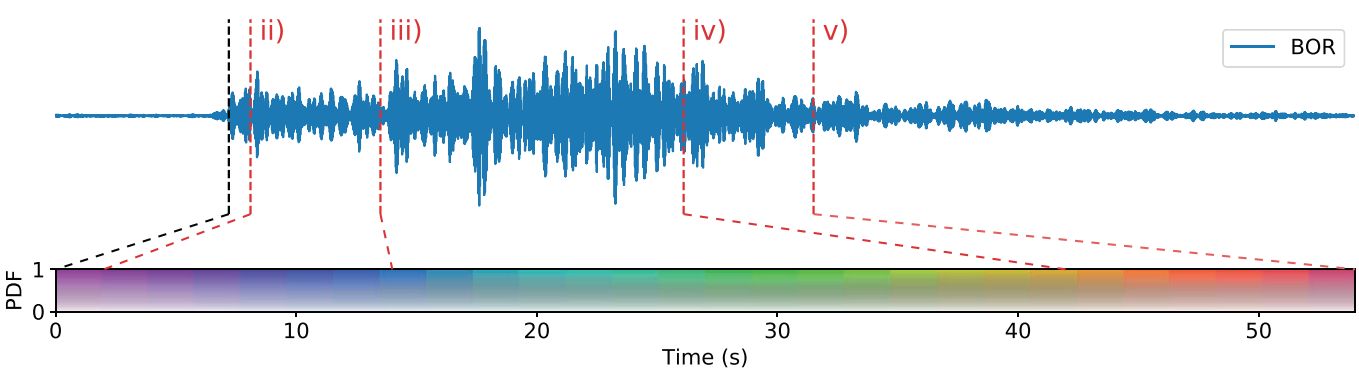

Figure 8. Spatio-temporal rockfall evolution. Color represents time of seismic record and intensity representing probability of source location. Black-shaded zone indicates rockfall trajectory from video. Black stars denote positions of maximum probability at time steps (ii) to (v). The seismogram underneath was recorded at closest station BOR at 13-17 Hz, associating time with color using a two-dimensional colorbar (MMesch, 2016). Signals recorded at all stations for all components are shown with scales in the supporting information. Using the results from the same simulation including topography, the pre-processing of synthetic and observed signals for location changes as follows: (a) Location at high-frequency band 13-17 Hz using all available station channels (ENZ, that is, east, north, and vertical components), thus $N_{\mathrm{Sta}}=7$. (b) Location at intermediate frequency band 8-12 Hz, with all components $E N Z$, that is, $N_{\mathrm{Sta}}=7$. (c) Location at low-frequency band 3-7 Hz, with all components $E N Z$, that is, $N_{\mathrm{Sta}}=7$. (d) Location at 13-17 Hz, with all components $E N Z$, that is, $N_{\text {Sta }}=7$, without site effect correction. (e) Location at $13-17 \mathrm{~Hz}$, using only vertical component $Z$, that is, $N_{\mathrm{Sta}}=3$. (f) Location at $13-17 \mathrm{~Hz}$, using vertical component $Z$, that is, $N_{\text {Sta }}=3$, and using simulations from a model with a flat surface.

location accuracies decrease. Pérez-Guillén et al. (2019) use the ASL technique in a sliding window to track snow avalanches and slush flows. When comparing the locations from seismic signals to numerical flow simulations, they report mean locating accuracies between 85 and $271 \mathrm{~m}$, which is of a similar order of magnitude to the results presented here.

Figure $8 \mathrm{~d}$ shows the location results without prior correction of the recorded signals from site amplification. The results fail to predict a clear rockfall trajectory and a large spatial discrepancy is observed between probable source positions and actual rockfall location.

In Figure 8e, the rockfall is located using seismic signals of only vertical component $Z$, leading to $N_{\text {Sta }}=3$ station-channel pairs. A narrow corridor of high probabilities can be seen, indicating a well resolved rockfall trajectory. However, compared to the results in Figure 8a, a larger discrepancy with the actual rockfall location is observed. This suggest that adding additional measurements may reduce the resolution as it becomes harder to keep the misfit, as defined in Equation 2, small, however, the predictions potentially 
improve as noisy or malfunctioning measurements can be compensated, which is in agreement with the network resolution study in Section 5.2.

In Figure 8f, locating is carried out using simulated energy ratios from a model with a flat surface. In this case, only vertical components can be used as energy ratios from horizontal components lead to values that are strongly modulated by radiation patterns, as shown in Figure 5. The resulting source probability distribution consists of patch-like areas that do not show smooth transitions over time (i.e., color), leading to a coarse rockfall location that is not well resolved in time. This is because the energy ratios from the flat model are dominated by the source-receiver distances and only these localized patches can explain the observed energy ratios. Typically, rockfall location methods attempt to account for the effect of the topography during the location process by considering a map of elongated travel times (e.g., Dietze et al., 2017; Hibert et al., 2014; Levy et al., 2015), assuming straight wave paths along the surface. The method proposed here allows the high-resolution topography and its influence on the wave field to be fully accounted for by 3D numerical modeling of the seismic wave field. The influence on the location by implementing a slightly coarser resolution DEM is demonstrated in Section 5.3.

\subsection{Locating Other Rockfalls}

The comparison in the previous section suggests that the best locating results for the present study site can be achieved in the high-frequency range (13-17 Hz), using both vertical and horizontal components (ENZ), removing site effects from the observed signals, and simulating energy ratios on the model with topography. With this configuration, the location method will now be evaluated using four rockfalls of different types and from different locations within the Dolomieu crater. The observed trajectories as well as the locations are shown in Figure 9 and described below.

Rockfall (a) is again located in the southwestern region, with an initial detachment further north compared to the previously analyzed event. Rockfall (b) is in the southeast and rockfall (c) is in the north of the Dolomieu crater. Rockfall (d) occurred in the same region as rockfall (c) but consisted of fine granular material in contrast to the other events which consisted of individual boulders.

For rockfall (a), Figure 9a, the most probable sources are all inferred at locations close to the observed trajectory in the southwestern region of Dolomieu crater. In particular, the location of the detachment phase (in purple) and the observed trajectory toward the east are well represented. However, for the last stage of the rockfall, inferred sources are located too far south, at the wall of the crater, and not at the bottom of the crater as observed. This might be interpreted as the signature of possible superposition of the seismic signals generated by subsequent boulders or an incorrect topography representation. Note that the resolution of the location method makes it possible to identify the trajectory and the detachment of this rockfall event distinctly with respect to the trajectory and detachment of the event analyzed in the previous section, Figure 8, for which the detachment phase is located $100 \mathrm{~m}$ further south.

For rockfall (b), Figure 9b, the inferred sources are correctly located in the southern region of the Dolomieu crater, but with strongly deteriorated resolution in space and time. The inferred source locations $30 \mathrm{~s}$ after the start of the event (in green), are located at the bottom of the crater. The video shows that the first boulder arrives at the crater bottom at this time, but other boulders are still moving at the top of the crater wall. Multiple sources hamper the ability of the location method to determine the trajectory of a single source. As a result, the inferred sources at later times (yellow and red colors) are located half-way down at the crater wall. Another explanation for the poor resolution is the station network configuration which will be studied in Section 5.2 using synthetic signals.

For rockfall (c), Figure 9c, the inferred sources are well-located at the beginning of the event, while locations become more and more scattered in space at later times. This time-deterioration of the resolution can be analyzed with the help of the video that shows that at beginning the event initially involves a single boulder impacting the crater wall, with subsequent distribution of boulders originating from the fragmentation of the original boulder or from the mobilization of basal rock deposits.

Finally for rockfall (d), Figure 9d, which occurred in the same region as event (c) but consisted of fine granular material flowing down the steep crater wall, the method is able to locate the event with high-resolution, 

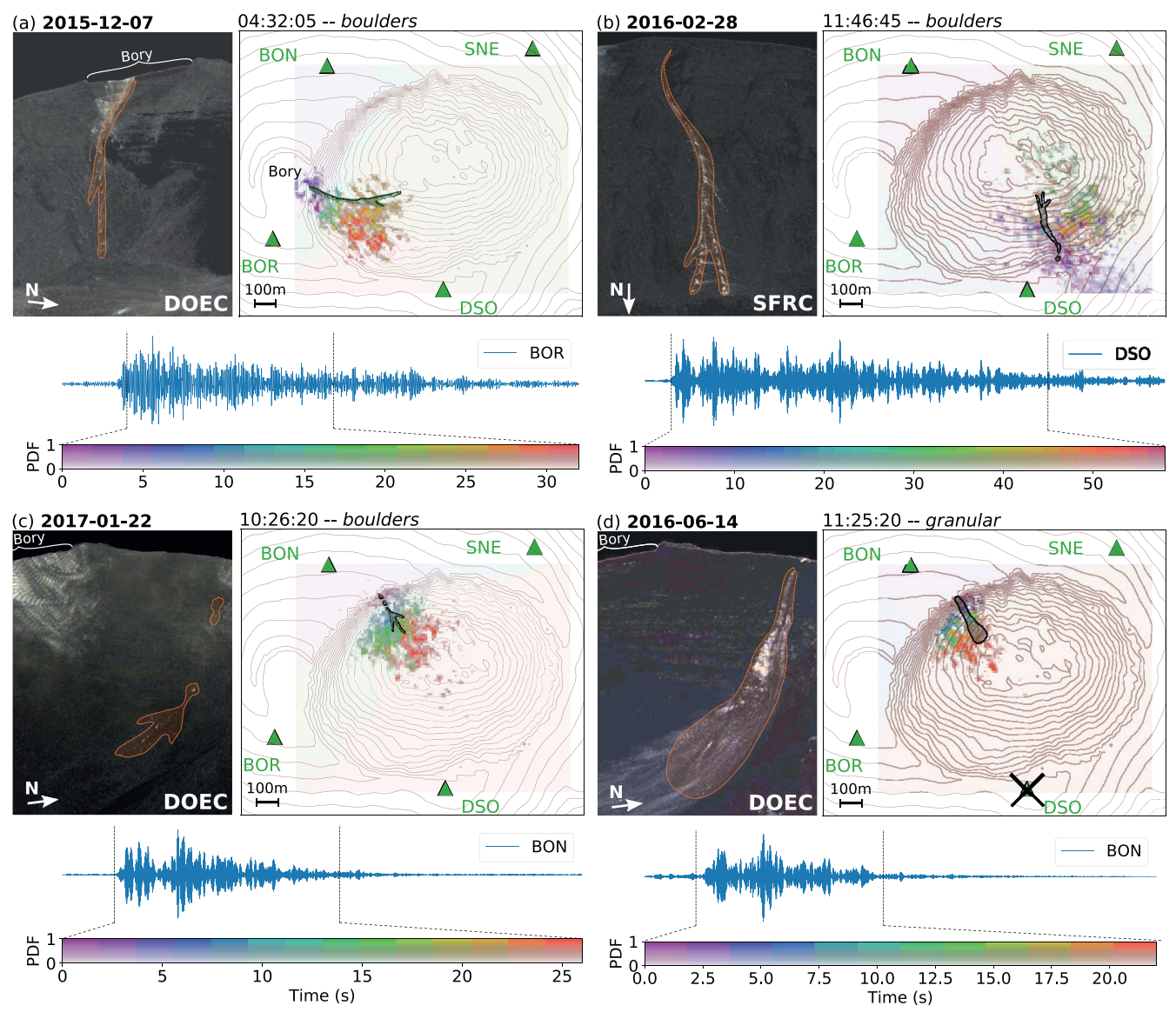

Figure 9. Four rockfalls used for locating evaluation. Left: Trajectory reconstructed from successive camera images (outline marked in orange and north-direction and camera indicated at the bottom). Right: Map of predicted spatiotemporal source evolution (black-shaded video-estimated trajectory). Underneath: Seismograms recorded at closest station (vertical ground velocity, bandpass filtered at 13-17 Hz). Signals recorded at all stations for all components are shown with scales in the supporting information. (a) Rockfall consisting of individual boulders occurring on December 7, 2015 in the southwest with detachment position just beneath Bory crater. (b) Rockfall consisting of individual boulders occurring on February 28, 2016 in the south. (c) Rockfall consisting of individual boulders occurring on January 22, 2017 in the north. (d) Rockfall consisting of fine granular material occurring on June 14, 2016; traces from dust clouds extend beyond the outlines of the sketched event location and station DSO was malfunctioning and could not be used for locating.

in particular the initial activation location. This is quite remarkable given that station DSO was not functioning properly and was disregarded for the analysis. Moreover, given that the source is parametrized as a single force, this high resolution of the source locations in the case of granular flow is not intuitive as it generates a complex extended source. This might suggest that recorded signals are dominated by a localized high-energy radiating source area, which we will further discuss in Section 5.4. Using a similar approach based on analyzing the seismic signals in a sliding time window, Pérez-Guillén et al. (2019) are also able to track the distributed and moving seismic sources generated by snow avalanches and slush flows.

\section{Evaluation of the Presented Location Method Using Synthetic Signals}

Rockfall events generate complex and extended seismic sources, and the resolution and the limitations of the proposed location methods need to be assessed through tests with synthetic seismograms for which the seismic sources can be controlled, for example, with known source time functions and locations. In this way, we study the problem of the superposition of spatially distributed sources as well as the performance of the location method in different frequency bands and the error introduced when topography is 
not considered. The study with synthetic seismograms additionally offers the possibility to evaluate the influence of the network geometry on the location resolution.

\subsection{Single-Point Sources Mimicking Boulder Impacts}

In order to assess the frequency-dependent location error introduced when topography effects are ignored, synthetic seismic signals are generated for two controlled point sources (e.g., two distinct boulders impacting at the same time with the same force, located in the southwestern part of Dolomieu crater) through 3D wave simulation in the model including topography. Locations of the sources are then inferred from different frequency bands of the synthetic signals using the location method with and without topography effects. For better comparability between these two cases, only vertical component signals are used for location. Figure 10 summarizes the main results. The true locations of the two point sources are located in the center of the red circles.

The left and middle columns show the inferred locations when considering sources at position P1 and P2 separately and the right column when the two sources are acting simultaneously. Rows a-d show the inferred locations when considering two frequency bands of the synthetic signals (i.e., 13-17 and 3-7 Hz) and propagating models with topography or a flat surface.

For the high-frequency band, Figure 10a shows the results when using propagating models including topography effects. The true positions of the sources P1 and P2, when considered acting separately, are well reconstructed as would be expected, corresponding to a point with high probability (i.e., dark purple) in the center of the red circles. In contrast, when using a flat propagating model, Figure 10b, sources are reconstructed with a 100-200-m location error and with a spatial ambiguity (multiple source positions with similar probability).

For the low-frequency band, when including topographic effects, Figure 10c, the location of the source P1 is well reconstructed, while the location is more ambiguous for the source P2 and spatially scattered within an area of size up to $300 \mathrm{~m}$. The imperfect location could be caused by the $4 \mathrm{~s}$ time window cutting a part of the low-frequency signal. As expected, when topographic effects are not included (flat model), Figure 10d, the inferred locations become more blurred. With longer probing wavelengths (i.e., for the low-frequency band), we would expect reduced location resolution for both models. The good reconstruction of source P1 in this low-frequency band for the model with topography is therefore puzzling. This cannot be explained by the proximity of station BOR, since better resolution of the source P1 would in that case also be observed when using the flat model. This might be the signature of topography effects, since the source P1 is located just below the crater rim, one of the steepest regions of the crater geometry, leading to generated signal characteristics quite distinct from those of neighboring potential locations.

When both sources are acting simultaneously (Figure 10, right column), positions of the individual sources can no longer be determined for all the test cases. Taking into account topography effects, Figures 10a and 10c, the probability distribution of source location inferred from the high-frequency band (Figure 10a) is spatially scattered with relatively high probability patches of around $300 \mathrm{~m}$ size in the neighborhood of the individual sources, while the distribution inferred from the low-frequency band is focused in a single region that seems to best explain the superposed signal from the two impacts. In other words, a single source in this region would result in similar relative energy measurements at the stations as the superimposed signal from the two sources. Interestingly, a small shift to the south is observed, similar to what occurs when locating real rockfalls in this area (see Figures $8 \mathrm{a}$ and $9 \mathrm{a}$ ), suggesting that the observed shift could partly be caused by the superposition of impacts from several boulders at different locations.

When ignoring topographic effects with the flat wave propagating model, Figures 10b and 10d, the inferred probability distribution of source location becomes smoother and less spatially resolved, since recorded seismic signals then contain only information on the source-receiver distances. For the low-frequency band, the relatively high-probability areas are loosely defined and shift further away from the actual source positions.

To summarize, the individual sources can be well-located only from high frequencies and when taking into account topography effects. When the two sources are acting simultaneously, that is, impacting at the same time and with same force, the individual sources can no longer be distinguished and the location 

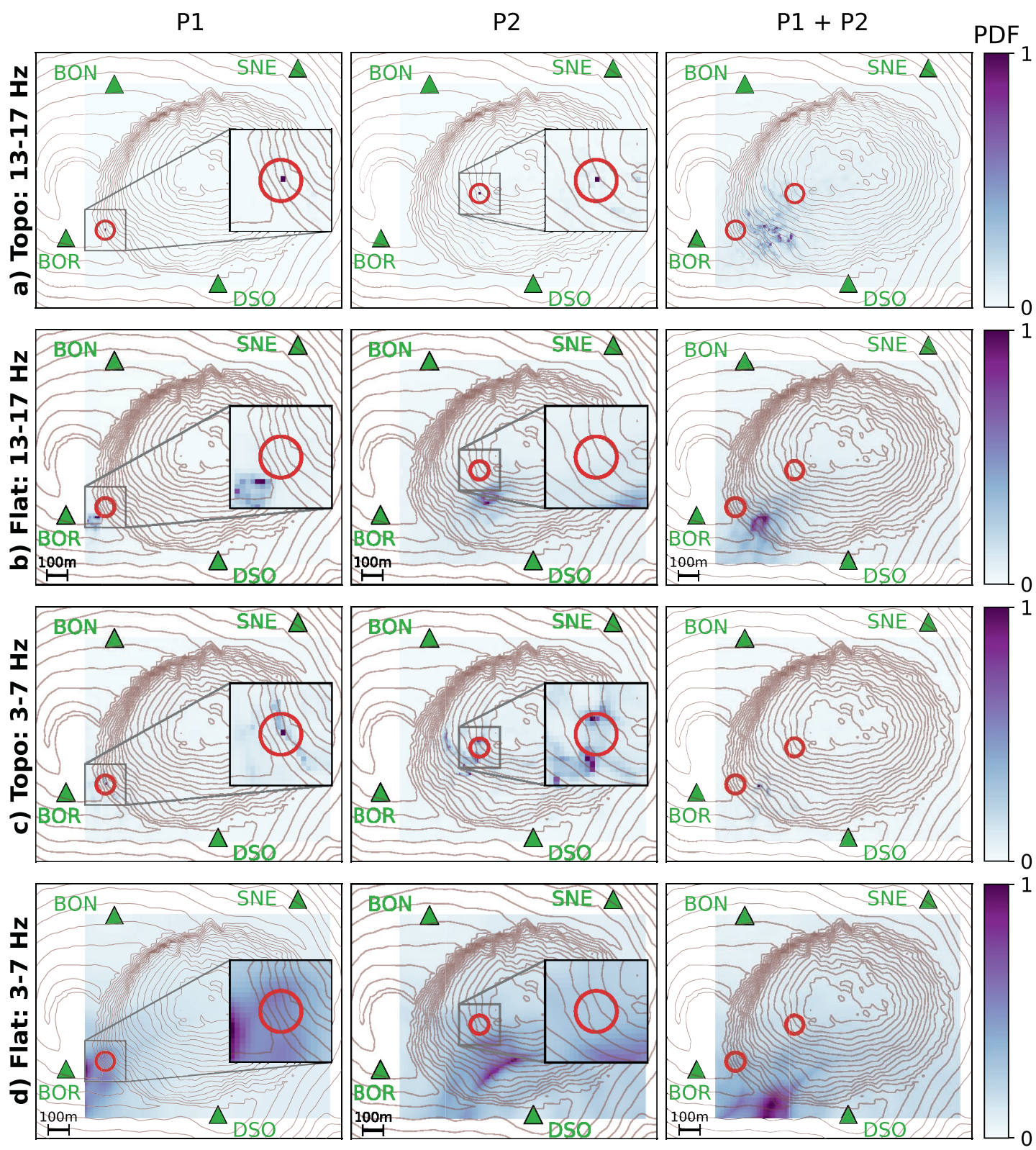

Figure 10. Location of point source at positions $\mathrm{P} 1$ and $\mathrm{P} 2$ and after simultaneously activating $\mathrm{P} 1$ and $\mathrm{P} 2$. The exact source position is located in the center of the corresponding red circle. Location is performed using vertical component $Z$, that is, $N_{\mathrm{Sta}}=3$. In each map, the color is normalized by the maximum probability. (a) Location of signals in frequency band 13-17 Hz using simulations from the domain with topography. (b) Location of signals in frequency band 13-17 Hz using simulations from the domain with a flat surface. (c) Location of signals in frequency band 3-7 Hz using simulations from the domain with topography. (d) Location of signals in frequency band 3-7 Hz using simulations from the domain with a flat surface.

probabilities are concentrated somewhere in the vicinity between the sources. Similar results were reported by Kumagai et al. (2009) who numerically tested the ASL method with two simultaneous, spatially separated sources, resulting in the best location being between the two sources. Nonetheless it is important to bear in mind that for real rockfalls, radiating sources are non-uniform in space and time. This means that recorded signals are dominated by the signature of the most strongly radiating sources at a given time. This makes it possible to locate the strongest sources in space at each time and to reconstruct rockfall trajectories reasonably well. 
(a)
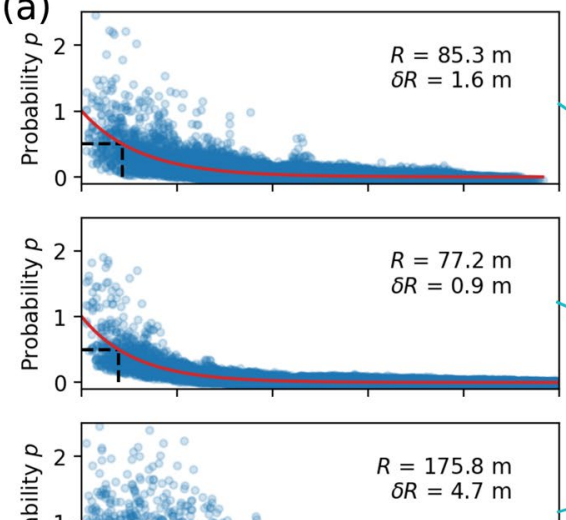

$$
\begin{aligned}
& \text { 흠 } \\
& \text { 은 }
\end{aligned}
$$

0

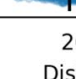

Figure 11. Resolution proxy $R$ from a network of four stations with vertical components. (a) Source location probability as a function of distance from the actual source at P1, P2, and P3, respectively. Blue circles in the distribution correspond to all the other grid points of potential source locations. The fitted exponential function is shown in red. Black dashed lines mark the position of resolution proxy $R$, defined by the half-decay. The plots are normalized so that $p(0)=1$ and $p(d \rightarrow \infty)=0$. (b) Map of the resolution proxy $R$, constructed by calculating the halfdecay for each grid point in case it is the actual source, as shown for points P1, P2, and P3.

\subsection{The Influence of the Network Geometry on the Location Resolution}

The previous analysis is extended by quantifying the decay of the location probabilities as a function of distance from the actual source. In this way, a proxy for the spatial resolution is defined for each grid point, which can serve as an array response function for single-impact sources.

Considering each grid point as the actual source position, the location probability of all other grid points is calculated (resulting in probability maps as in Figure 10). Then, assuming a circular symmetry of the probability as a first order approximation, the source probability $p$ as a function of distance $d$ from the actual source is approximated by an exponential decay of the following form:

$$
p(d)=a \exp (-d k)+b,
$$

where $a, k$, and $b$ are fitting parameters. The fit is performed without considering the probability value at the actual source position to avoid influence from singularities (such as the high probability at the source position in Figure 10a). Finally, a proxy $R$ for the spatial resolution is defined by the half-life of the exponential decay using rate constant $k$ :

$$
R=\frac{\ln (2)}{k}
$$

The shift $b$ can be ignored, since only relative probability variations are important.

Figure 11 presents the analysis performed for a network using the vertical components $Z$ of all four stations. The decay of probabilities with distance is shown for three points as example in Figure 11a, where points P1 and P2 correspond to the points analyzed in Figure 10. The fitted exponential function is shown in red and half-decay is marked with black dashed lines. The uncertainty $\delta R$ on resolution proxy $R$ has been propagated from the fitting error $\delta k$ in the rate constant $k$.

The map of resolution proxy $R$ in Figure $11 \mathrm{~b}$ shows a median resolution of $R_{\mathrm{med}}=107.4 \mathrm{~m}$ and generally indicates values below $100 \mathrm{~m}$ in the northwest (as for points P1 and P2) and values above $100 \mathrm{~m}$ in the southeast (as for point P3). The southeastern region is not enclosed by the network geometry which may explain the poorer resolution. The poorer resolution in the vicinity of station DSO may be caused by the proximity of this station to the crater rim, suggesting that this is not an optimal position for locating seismic sources. 

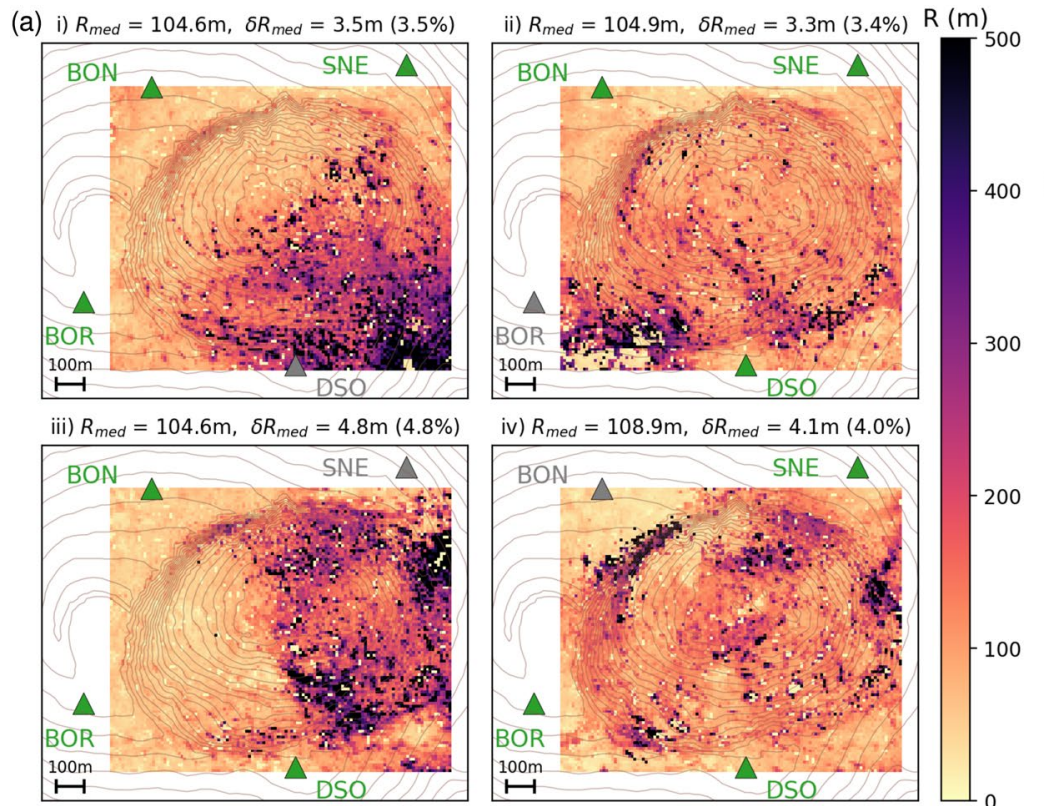

(b)
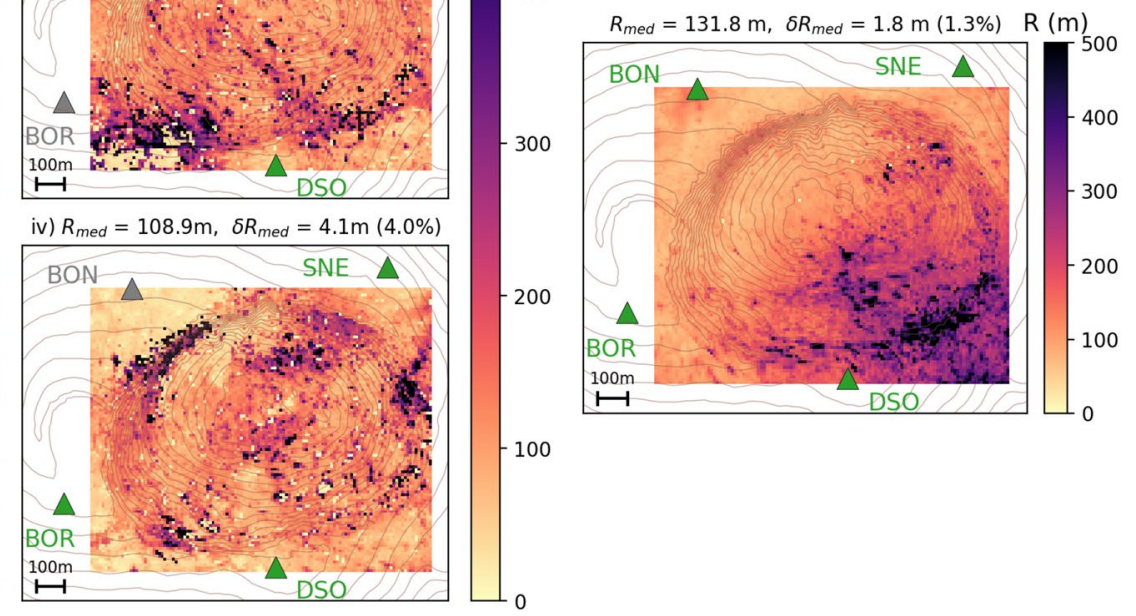

Figure 12. Influence of the network geometry on the resolution proxy $R$. (a) Map of resolution when using three stations of vertical components $Z$. Removed station is shown in gray. Station combinations consist of (i) BON-BOR-SNE, (ii) BON-DSO-SNE, (iii) BON-BOR-DSO, and (iv) BOR-DSO-SNE. (b) Map of resolution when using four stations and all available channels, that is, three component $E N Z$ of stations BON, BOR, and SNE; vertical component $Z$ of station DSO.

To evaluate the influence of the network geometry on the resolution, the analysis was performed with one of the stations removed alternately. Figure 12a shows the resulting maps of resolution proxy $R$ using a reduced network of three stations with vertical components only. Generally, the resolution becomes poorer in the direction of the removed station while the three remaining stations form a triangle that spans an area of enhanced resolution, best seen in (i) and (iii). This triangle is not so clearly visible in (ii) and (iv) because of the generally poorer resolution in the southeast (see Figure 11b).

The median resolution $R_{\text {med }}$ decreases slightly compared to the previous analysis with four stations (except for case iv). If fewer stations are involved, the accumulated misfit at positions in the vicinity of the actual source is lower, resulting in higher probabilities and steeper decay of the exponential curve. However, the relative median uncertainty $R_{\text {med }}$ increases by a factor between 2 and 3 (from $1.7 \%$ to $3.4 \%-4.8 \%$ ), indicating a more scattered probability distribution.

On the contrary, adding measurements increases the median resolution as can be seen in Figure 12b with $R_{\text {med }}=131.8 \mathrm{~m}$, where all available station components have been combined (i.e., three components of BON, BOR, and SNE, and vertical component of DSO). Nevertheless, the relative median uncertainty decreases to $1.3 \%$ and the spatial variation of the resolution is smoother compared to the response from vertical components only (Figure 11b). This suggests that the location method is more stable with an increased number of measurements which help to better determine the solution space. This is analogous to findings of Kraft et al. (2013) whose optimal network design algorithm, which takes into account laterally variable noise levels, often extends an established network with stations near existing station locations to further enhance the seismic source resolution. Their algorithm is based on the linearized earthquake location problem (D-criterion), first implemented by Kijko (1977). Toledo et al. (2020) use the same theory to develop a network design tool for seismic sources in geothermal and volcanic contexts. Their study shows how the first four stations can significantly improve the cost-benefit given optimal locations, while the added value decreases with each additional station in a power-law like manner.

For the given network at Dolomieu crater, the above tests indicate enhanced resolution in the area which is enclosed by the network geometry. This is an effect which can be observed in previous rockfall location studies (e.g., Gracchi et al., 2017; Lacroix \& Helmstetter, 2011) and agrees with findings from optimal network design studies (e.g., Rabinowitz \& Steinberg, 1990). In the present case, the southeast part of the crater 
shows lower resolution, explaining the poor location of the rockfall on February 28, 2016, in Figure 9b. Adding additional measurements, such as horizontal channels, can increase the stability of the solution with only a slight loss of resolution, which is especially important in the field when measurements can be contaminated by noise or when the site amplification functions are poorly known, which is in agreement to the rockfall location results in Figures $8 \mathrm{a}$ and $8 \mathrm{e}$ using three components (ENZ) and the vertical component $(Z)$, respectively.

\subsection{Multiple-Point Sources Mimicking a Down-Slope Moving Rockfall}

Synthetic rockfall seismic signals are generated here from a downward moving seismic point source, that is, parametrized as a single vertical traction, kinematically constrained by the boulder trajectory observed during one rockfall event at the Dolomieu crater (December 13, 2016) already discussed in Section 4.1. The space-and-time positions of the seismic point-source is mapped in Figure 13. Another representation of the space-time trajectory of the seismic source is shown in the graph at the top of Figure 14a.

To construct the source space-and-time trajectory of the point-source, the position and time of seven markers (Figure 14a) during the rockfall were determined manually from the analysis of the video images of the rockfall event on December 13, 2016. The time and space positions of the source between the selected markers are interpolated including small fluctuations using the $10 \times 10 \mathrm{~m}$ spatial grid covering the observed rockfall trajectory, leading to a total of $200 \mathrm{impacts}$. The source can be activated at the same spatial position a number of times as the trajectory is spatially discretized by only 60 cells.

Synthetic seismic signals, hereafter designated the reference signals, are generated at the different stations from all the source positions and activation times, using the wave propagating model including topography. The source-time function ( $7 \mathrm{~Hz}$ Ricker wavelet) and the amplitude of the vertical traction are the same for all the impact sources. The corresponding generated signals can be seen in Figure A1b.

In the test, the location method is applied using: (1) the same topographic model used for the generated reference signals, in a high-frequency (13-17 Hz, defined as baseline model) and a low-frequency (8-12 Hz) band of the reference signals (Figures 13a and 13b, respectively); (2) a wave propagating model including a low-pass filtered topography with a $30 \mathrm{~m}$ corner wavelength reducing the topography resolution from 10 to $20 \mathrm{~m}$ (Figure 13c); and (3) a wave propagating model including the original topography but a velocity model increased by $10 \%$ (Figure 13d). Further, the influence of the assumption of vertical rockfall impacts is tested by synthesizing reference signals generated by source impacts normal to the slope and locating them using the same wave propagation model as above from vertical sources (Figure 13e) and a wave propagation model from slope-normal sources (Figure 13f). Finally the method is tested after adding different levels of white noise to the reference signal (Figures 13g-13i).

Results in Figure 13a are expected to be best because the synthetic signals are analyzed using the same model used for their generation and because the best spatial resolution is expected at high frequencies as already seen before. Nevertheless, in contrast to a single-point source which could be located exactly (Figure 10a), we can observe a corridor of high probability that extends to up to $200 \mathrm{~m}$. This is related to the superposition of signals from temporally overlapping sources, which compromises the predictions. Still, the predictions correctly follow the progressively downhill moving active source region.

The second low-frequency test, Figure 13b, demonstrates that valuable information is also contained in the low-frequency band, even though larger-wavelengths result in lower spatial resolution than when using high frequencies, extending the high probability corridor especially at later times to up to $300 \mathrm{~m}$. The contained information still suggests that developing methods that can exploit information across different frequency bands would be a major improvement, but is beyond the scope of this study.

In the third test, Figure 13c, in which the forward modeling part of the location method includes a smoother representation of the topography, inferred source locations are shifted compared to those inferred from first step, for example, the source positions between 20 and $30 \mathrm{~s}$ are shifted by around $50 \mathrm{~m}$ toward the south. This stresses the importance of properly resolving the topographic effects at the scale of the frequency bands that are analyzed. Besides the already discussed superposition of multiple sources at different locations, the observed southwards shift of the predicted trajectory in Section 4.1 can partly be interpreted as possibly 
(a) Baseline configuration

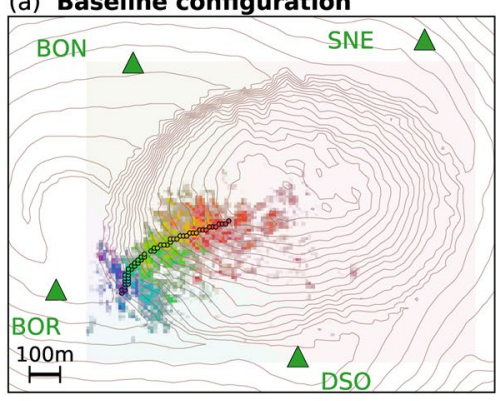

(d) Fast model ( $10 \%$ higher velocities)

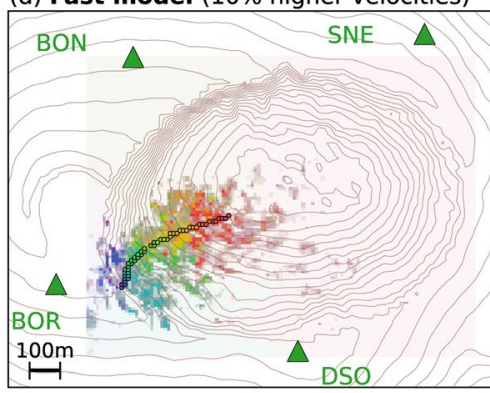

(g) SNR=30 (3.4\% median noise)
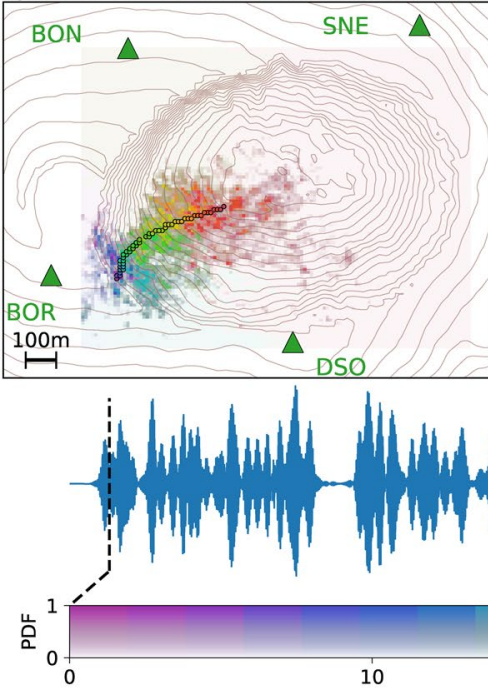

(b) Frequency band 8-12 $\mathbf{~ H z}$

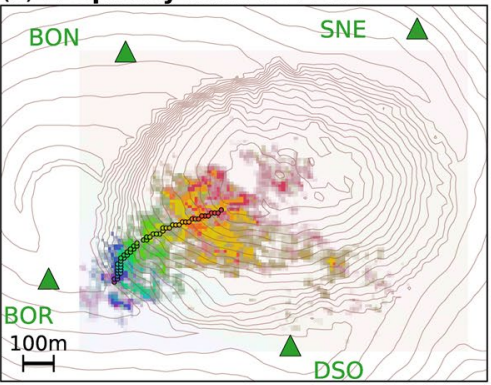

(e) $S_{n}$ signal $-S_{z}$ model

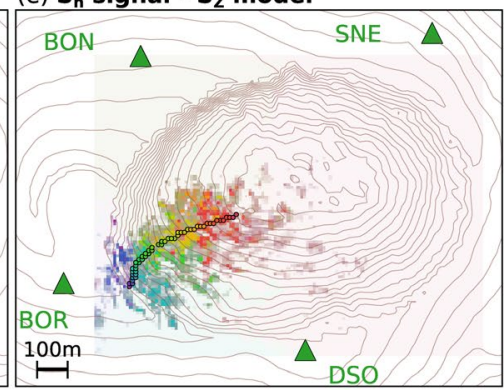

(h) SNR=2.4 (41\% median noise)

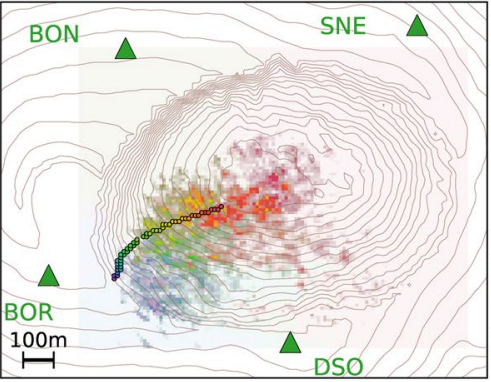

(c) Topo $20 \mathrm{~m}$ resolution

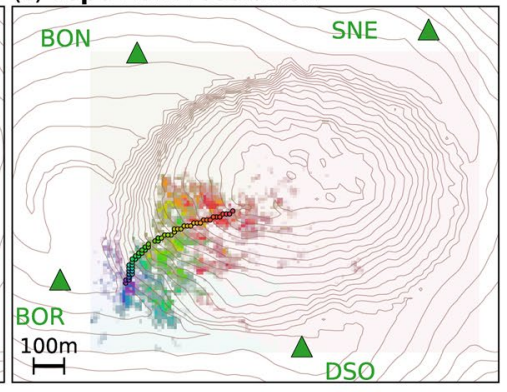

(f) $S_{n}$ signal $-S_{n}$ model

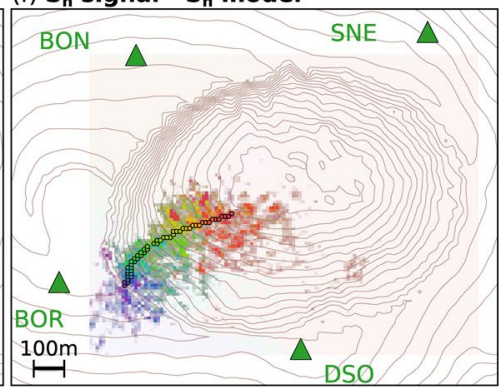

(i) SNR=1.4 (71\% median noise)

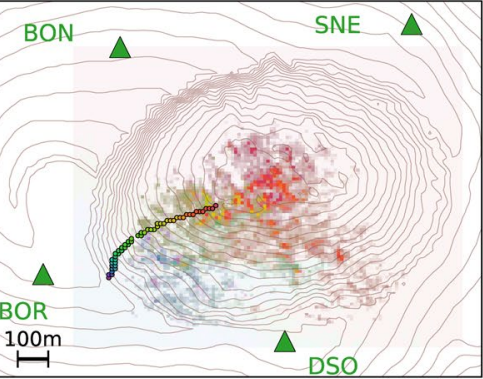

- BOR

$\mapsto$

Fure 13. Location of a synthetic signal for a single rock moving down-slope. Color-filled circles mark the space-and-time positions of the vertical point impacts. The bottom graph shows the generated seismogram (vertical velocity) recorded at BOR and filtered at $13-17 \mathrm{~Hz}$, resulting from a total of 200 impacts (the low amplitude gap in the signal is random and corresponds to the gap at around $12 \mathrm{~s}$ in the offset-delay distribution in Figure 14a). Signals generated at all stations for all components are shown with scales in Figure A1. (a) Baseline configuration for location at 13-17 Hz using a wave propagation model with a topography resolution of $10 \mathrm{~m}$ and all station-channel pairs $\left(N_{\mathrm{Sta}}=7\right)$. (b) Location in a lower frequency band at 8-12 Hz. (c) Location using a wave propagation model with a topography resolution of $20 \mathrm{~m}$. (d) Location using a wave propagation model with a $10 \%$ faster medium velocity. (e) Location of a synthetic rockfall signal from sources that are directed normal to the topography, referred to as $\mathrm{S}_{\mathrm{n}}$, using a wave propagation model with vertical sources $\mathrm{S}_{\mathrm{Z}}$. (f) Location of a synthetic rockfall signal from sources which are directed normal to the topography, referred to as $\mathrm{S}_{\mathrm{n}}$, using a wave propagation model with normal sources $\mathrm{S}_{\mathrm{n}}$. $(\mathrm{g})$ Location of a reference signal contaminated by a median white noise level of $3.4 \%$, corresponding to a median signal-to-noise ratio SNR $\approx 30$, comparable to the noise level observed in this frequency band for the previously analyzed and relatively small rockfall on December 13, 2016 (see Appendix A). (h) Location of reference signal with median SNR $\approx 2.4$ (Figure A2b). (i) Location of reference signal with median SNR $\approx 1.4$ (Figure A2c).

resulting from an inaccurate outdated DEM given that the surface topography of the Dolomieu crater is continuously reshaped by high rockfall activity (e.g., Derrien et al., 2019; Durand et al., 2018; Hibert, Mangeney, et al., 2017). Which of the two effects is stronger is inherently dependent on the location of the rockfall and the relative positions and magnitudes of the inferring sources, and cannot be predicted in a general way. 
a) Two successive boulders, 200 impacts each
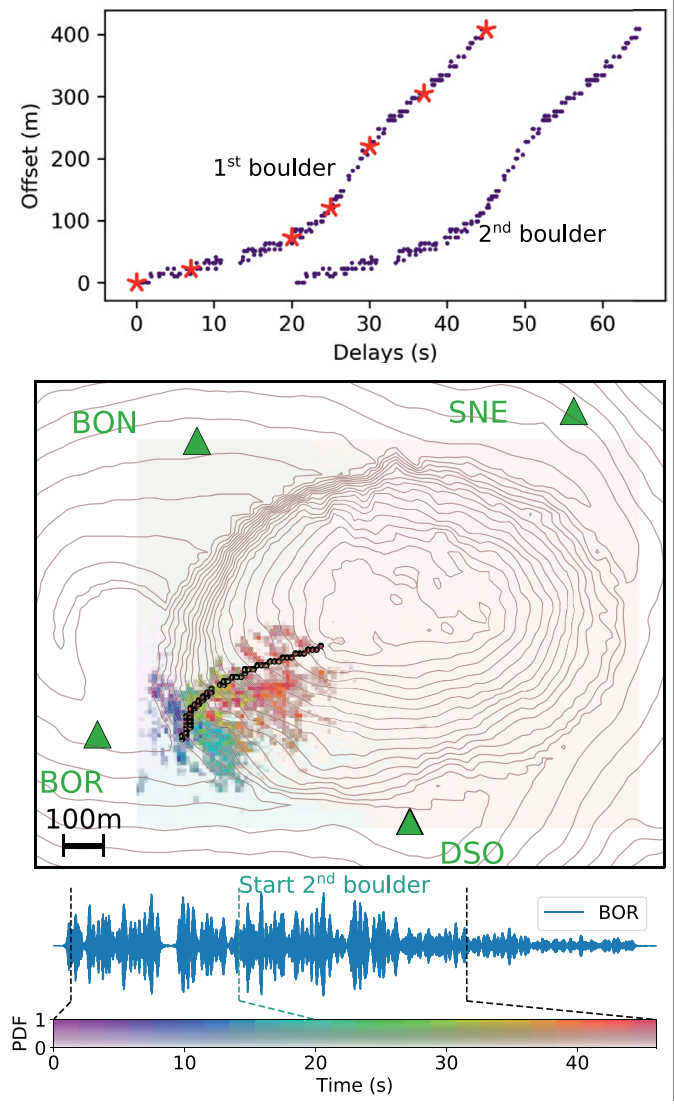

b) Granular event with 10,000 impacts
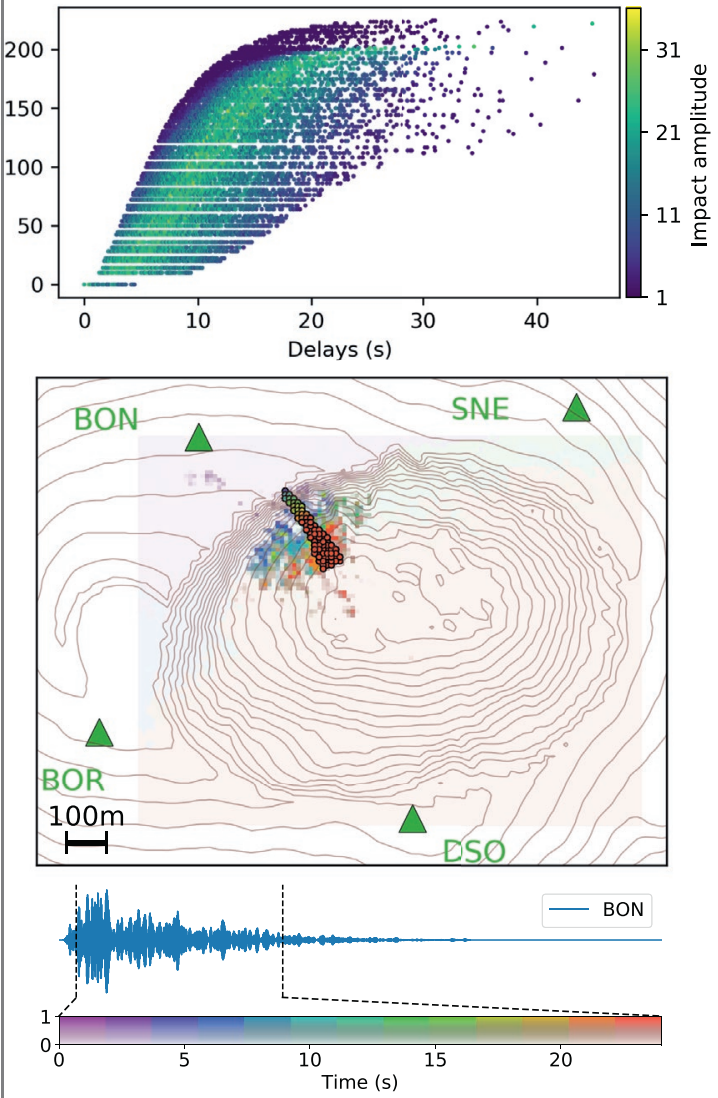

Figure 14. (a) The graph on top shows space-time distribution of two source trajectories mimicking two successive boulder tracks of 200 impacts each. Red asterisks mark source locations of the rockfall on December 13, 2016 as estimated from video images that serve as interpolation points. Under the map, the generated reference signal is shown, recorded at BOR and filtered at 13-17 Hz. The map shows picked source positions as well as location results at 13-17 $\mathrm{Hz}$ using a wave propagation model with a topography of $10 \mathrm{~m}$ resolution. (b) Space-time distribution of 10,000 sources mimicking a granular flow. The sources are distributed within two velocity curves. An additional curve in-between defines sources of maximum impact amplitude. The amplitude is represented in arbitrary units with a minimum amplitude of 1 . Under the map, the generated reference signal is shown, recorded at BON and filtered at 13-17 Hz. Signals generated at all stations for all components are shown with scales in Figure A1. Note that the signal amplitude is controlled by both the amplitude of each individual impact and the number of sources that act simultaneously. The map shows picked source positions as well as location results at $13-17 \mathrm{~Hz}$ using a wave propagation model with a topography of $10 \mathrm{~m}$ resolution.

To better understand the influence of the velocity model for the source predictions, the location method is applied using a wave propagation model including the original topography but with a modified velocity model in which velocities are globally increased by $10 \%$, Figure 13d. This also influences intrinsic attenuation by decreasing the velocity-dependent absorption coefficient (e.g., Aki \& Richards, 2002). The inferred source locations do not differ significantly from the best reference test with the original velocity model, Figure 13a, in the same frequency band. This might appear to be surprising as in this test the forward modeling part of the location method is computed using the same topography resolution but with a different velocity model. However, in this modified velocity model, seismic velocities are uniformly increased by $10 \%$, which does not significantly alter the energy ratios between the different stations. More systematic scenarios, including possible spatially localized velocity perturbations and local site effects at the stations, need to be investigated in the future to properly assess the influence of the a priori uncertainties in the seismic velocity model on the performance of the location method. In the case that information about the subsurface properties is available, it can be considered in the spectral-element based 3D propagation model and can therefore, taken into account in the proposed location method. This is in contrast to other locating 
methods where the seismic velocity is used as a free parameter and optimized during the locating process to maximize the correlation between stations (e.g., Burtin et al., 2013; Dietze et al., 2017; Hibert et al., 2014; Pérez-Guillén et al., 2019), therefore 3D velocity models cannot be considered.

The energy ratios from the wave propagation model are generally computed under a vertical source assumption, even though a rockfall can generate forces normal and tangential to the slope. Kuehnert et al. (2020) showed that wave propagation along the topography dominates over the source direction, suggesting that the source direction and the resulting radiation patterns are a second order effect for location. To support this assumption and verify that non-vertical forces generated from the rockfall on the ground can indeed be ignored, a new reference signal is generated from sources directed normal to the slope, which we refer to as the $\mathrm{S}_{\mathrm{n}}$-signal. In the test, the location method is then applied using a wave propagation model with vertical sources, referred to as the $\mathrm{S}_{\mathrm{Z}}$-model, Figure 13e; and using a wave propagation model with normal sources, referred to as the $\mathrm{S}_{\mathrm{n}}$-model, Figure $13 \mathrm{f}$.

Results from the first test with the vertical source assumption, Figure 13e, do not differ significantly from the previous test with a reference signal from vertical sources, Figure 13a, suggesting that the direction of the rockfall source impact does not influence the performance of the location method.

This conclusion is further supported by the second test using a wave propagation model with normal sources, Figure 13f, where the outline of the predicted source distribution is displaced by a maximum of $50 \mathrm{~m}$ compared to the previous distribution in Figure 13e. Given the unpredictability of the source field in the case of real rockfalls, we conclude that the vertical source assumption is very reasonable and the most straightforward solution when predicting rockfall trajectories with the proposed location method.

Finally, noise contaminated reference signals were located. In Figure 13g, the noise causes the probability distribution to be slightly blurred with location probabilities reducing by around $10 \%$ and the width of the spatial distribution increasing by around $100 \mathrm{~m}$ compared to the noise-free test in Figure 13a. Here, the added white noise is similar in amplitude as observed at $13-17 \mathrm{~Hz}$ in the signals from Dolomieu crater, that is, a median noise level of 3.4\% or median signal-to-noise ratio of SNR $=30.0$ for the rockfall on December 13, 2016, which does not comprise large volumes, as can be seen in Figure 6. Higher noise levels, Figures $13 \mathrm{~h}$ and 13i, increasingly blur the predicted source probability distribution with location probabilities reducing by around $30 \%$ and $70 \%$, and the width of the spatial distribution increasing by around 200 and $400 \mathrm{~m}$, respectively, compared to the noise-free test in Figure 13a. The tests suggest that the location method is robust to noise levels many times higher than those observed at Dolomieu crater, and that at an average SNR of 2.4, the rockfall trajectory can still be tracked reasonably well with an error of about $200 \mathrm{~m}$.

\subsection{Distributed Point Sources Mimicking Complex Rockfalls and Granular Flows}

To increase complexity, the downward moving seismic source is activated twice with a respective time shift of $20 \mathrm{~s}$, as shown in Figure 14a, where the top graph shows the space-time trajectory of two successive boulders. As a consequence of the respective time shift, the first boulder arrives at the bottom of the crater while the second boulder is still located in the top half of the crater wall, visible by the red-filled circles for times $>40 \mathrm{~s}$ in the map of Figure 14a.

Location results show a high probability corridor of around $200 \mathrm{~m}$ width comparable with the probability distribution from the single-boulder test in Figure 13a. However, the superposition of the two simultaneously acting sources compromises the time resolution of the method, that is, the color sequence is mixed so that, for example, the red color for times $>40 \mathrm{~s}$ is strongly scattered and spread along almost the whole crater wall. This loss of spatio-temporal resolution due to superposition of multiple sources was already observed in the previous test with single sources P1 and P2, Figure 10, and partly explains the poor spatio-temporal location of the rockfall on February 28, 2016, located on the southeastern crater wall, Figure 9b.

In a second test, a large distributed source with variable impact amplitudes was constructed, aiming to synthesize the characteristics of a granular flow. The space-time distribution of a total of 10,000 source impacts, presented in Figure 14b, is constructed by defining a minimum and a maximum velocity curve as well as a third curve in-between where impact amplitudes are maximum. The total number of impacts reaches its 
maximum at around $10 \mathrm{~s}$ and decays subsequently toward zero after $45 \mathrm{~s}$. The source area, marked by colorfilled circles on the map in Figure 14b, is spatially discretized by 87 cells (selected from the $10 \times 10 \mathrm{~m}$ spatial grid), each of which can be activated multiple times to simulate a total of 10,000 impacts. The corresponding generated signals are shown in Figure A1d.

Despite the superposition of the numerous distributed seismic sources, high probability predictions are correctly located on the northwestern crater wall. The width of the probability distribution of up to $300 \mathrm{~m}$ is very similar to the one from the real granular event on June 14, 2016, Figure 9d, and the global downward movement of the sources is well captured and can be followed by means of the correctly ordered color sequence.

\section{Conclusion}

We propose a new rockfall location method based on seismic energy ratios between stations. In an optimization routine, observed energy ratios are compared to a database of simulated energy ratios in a region of interest. The benefit of the method is that once the database has been created, locations can be estimated quickly without the need for complicated analyses of the seismic signal such as precise picking of arrival times. The rockfall seismic signals are analyzed in sliding time windows, making it possible to follow the rockfall trajectory over time. The method can therefore potentially be used for continuous monitoring in real time, in parallel with existing methods that detect and classify rockfall seismic signals (e.g., Dammeier et al., 2016; Dietze et al., 2017; Hibert, Provost, et al., 2017; E.-J. Lee et al., 2019; Maggi et al., 2017; Provost et al., 2017).

By direct numerical modeling of the wave field on a domain representing the study site, no assumptions about the wave type of the recorded signal are required, high-resolution surface topography and its influence on the wave field can be accounted for, and a priori information about subsurface properties and a corresponding 3D seismic velocity model can be considered and are not required to be estimated during the location process.

Here, location was performed for rockfalls at Dolomieu crater, Reunion Island. All analyzed rockfall events could be located in the correct area of the crater. Generally, the best spatial resolution (below $100 \mathrm{~m}$ ) is observed in the beginning of the rockfall when the seismic source is very confined in space. Thereafter, the predicted source locations become more scattered. This is linked to the spatial distribution of the seismic source, comprising multiple simultaneous impacts at different positions. The superposition of multiple sources is not considered in the method and hence compromises the location results. Nonetheless, the method performs remarkably well in this regard and is even able to locate a downward moving granular flow, likely because the signals are dominated by the signature of the most radiating sources at a given time.

It is shown that the influence of the assumed source impact direction on the location is of the second order, since propagation along the Dolomieu crater topography dominates over source-characteristic radiation patterns for the investigated frequencies above about $3 \mathrm{~Hz}$. Thus, a vertical surface traction can be assumed, even though the actual source field of real rockfalls remains unknown. Furthermore, the insignificance of the source-characteristic radiation patterns makes it possible to use all vertical and horizontal component signals for location, which makes the method more robust against ambient noise or poorly known site amplifications.

Experiments with synthetic rockfall sources confirmed that the best spatial resolution is achieved at high frequencies (here in the frequency band of 13-17 Hz). For future development of the method, a combination of multiple and possibly also narrower frequency bands should be considered. The synthetic tests also revealed that a precise representation of the surface topography is crucial to the quality of the location results.

Investigations on the influence of the network geometry on the resolution suggests that best resolution (below $100 \mathrm{~m}$ ) is achieved when the source area is triangulated by the seismic stations. The method currently assumes that the signal of a seismic source arrives fully within the defined time window at all stations. This is possible because of the positions of the seismometers with respect to the rockfalls at Dolomieu crater 
but might be a limitation for other source-receiver geometries. In order to overcome this limitation, a time shift can potentially be introduced at each station with respect to the region of interest after estimating the approximate arrival times.

Comparisons with other location methods that are able to track moving seismic surface sources, as for example the approach of ASL (e.g., Pérez-Guillén et al., 2019), need to be carried out at the same study site and using the same station network to assess the benefits of each method and compare their resolution.

Noise levels at Dolomieu crater are very low at the here studied frequencies above $3 \mathrm{~Hz}$ and could be ignored when locating the observed rockfalls. Tests with added white noise showed that the location method is robust against noise levels that are considerably higher than those observed at Dolomieu crater, and that using signals in the 13-17 Hz frequency band with an average SNR of 2.4, rockfall trajectories can still be tracked with an error of about $200 \mathrm{~m}$.

No significant effects on the location results were found when modifying the subsurface velocity model. However, seismic velocities in the test were uniformly increased by $10 \%$, which does not significantly alter the energy ratios between the different stations. More systematic scenarios, including possible spatially localized velocity perturbations and local site effects at the stations, will need to be investigated in future studies to properly assess the influence of the a priori uncertainties in the seismic velocity model on the performance of the location method.

\section{Appendix A: Comparison of Real, Synthetic, and Noise-Contaminated Synthetic Rockfall Signals}

Seismograms generated by the above analyzed rockfall events on December 13, 2016 and on June 14, 2016 are shown in Figures A1a and A1c, respectively. They are shown together with synthetic rockfall signals, mimicking the real events, in Figure A1b for the boulder-type event synthesized and analyzed in Section 5.3 and in Figure A1d for the granular-type event synthesized and analyzed in Section 5.4.

To test the location method with noise-contaminated synthetic signals, the noise levels on the observed signals at Dolomieu crater are analyzed using the rockfall event on December 13, 2016. Observed signals filtered at $13-17 \mathrm{~Hz}$ and corresponding signal-to-noise ratios (SNR) are shown in Figure A2a. The minimum SNR is 15.1 while the median SNR is 30.0, which corresponds to a median noise level of 3.4\%. For the relatively small rockfall, the SNR is high, which indicates a low noise level at the Dolomieu crater at these high frequencies.

White noise is now added to the synthetic rockfalls in Figure A1b. Figure A2a shows the synthetic signals contaminated with a noise level so that the median $\mathrm{SNR} \approx 30$, comparable to the SNR observed at Dolomieu crater. Noise levels are then increased by a factor of 12 and a factor of 21 , resulting in the synthetic signals shown in Figures A2b and A2c, respectively. A factor of 12 increases the median noise level to 41.5\% (i.e., median SNR $\approx 2.4$ ), hiding almost entirely the signal at station SNE. A factor 21 increases the median noise level to $71.0 \%$ (i.e., median SNR $\approx 1.4$ ), hiding not only signals at SNE, but also at BON. 


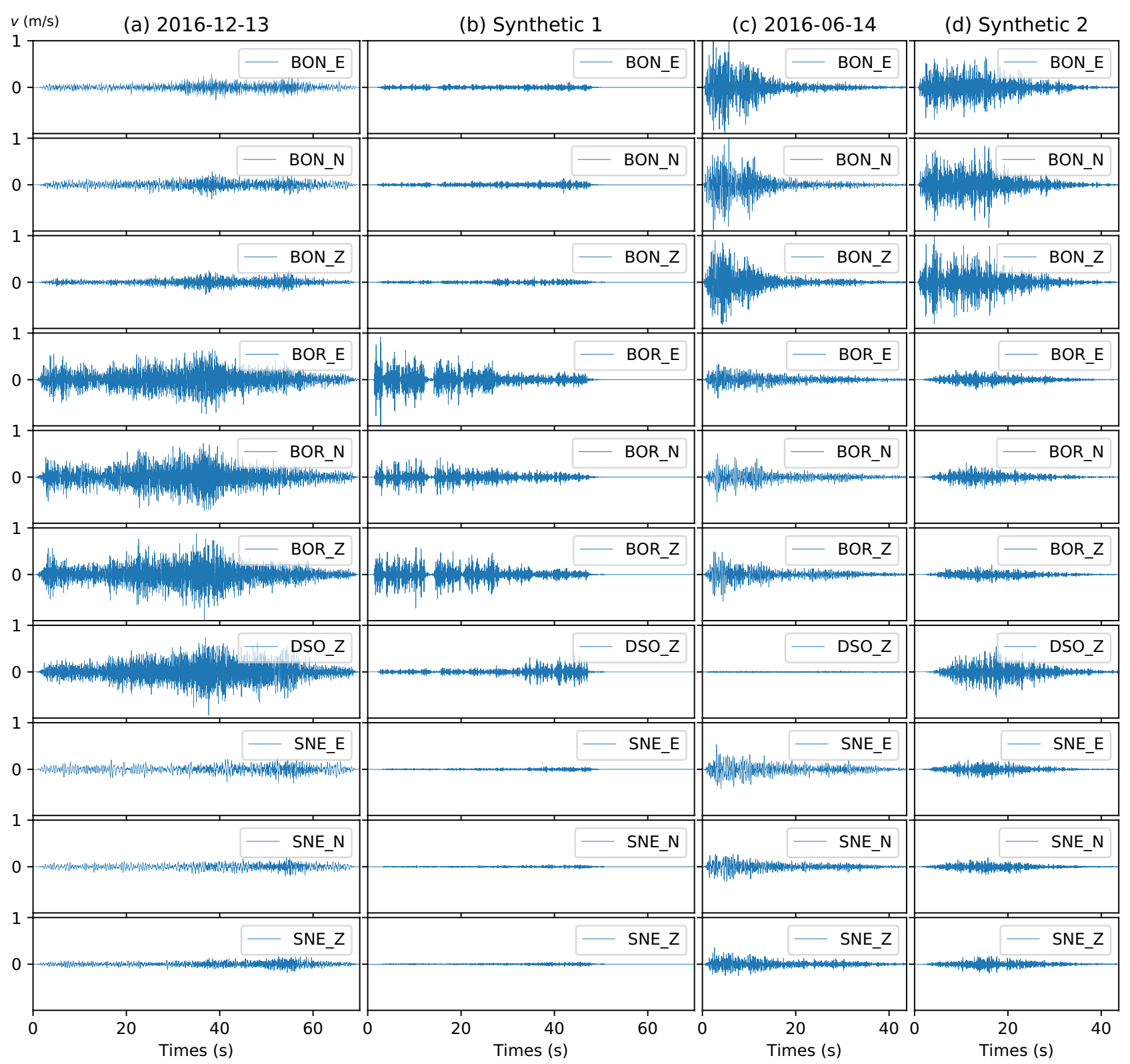

Figure A1. Seismograms of all station channels for real rockfalls at Dolomieu crater and synthetic signals mimicking these events. Signals of each event are normalized and real seismograms are bandpass filtered at 1-35 Hz. (a) Signals of boulder-type event on December 13, 2016, analyzed in Figures 6-8. (b) Synthetic signals generated by 200 point impacts mimicking a down-slope moving rock, analyzed in Figure 13. (c) Signals of granular-type event on June 14, 2016, analyzed in Figure 9d. (d) Synthetic signals generated by 10,000 point impacts mimicking a granular flow, analyzed in Figure 14. 


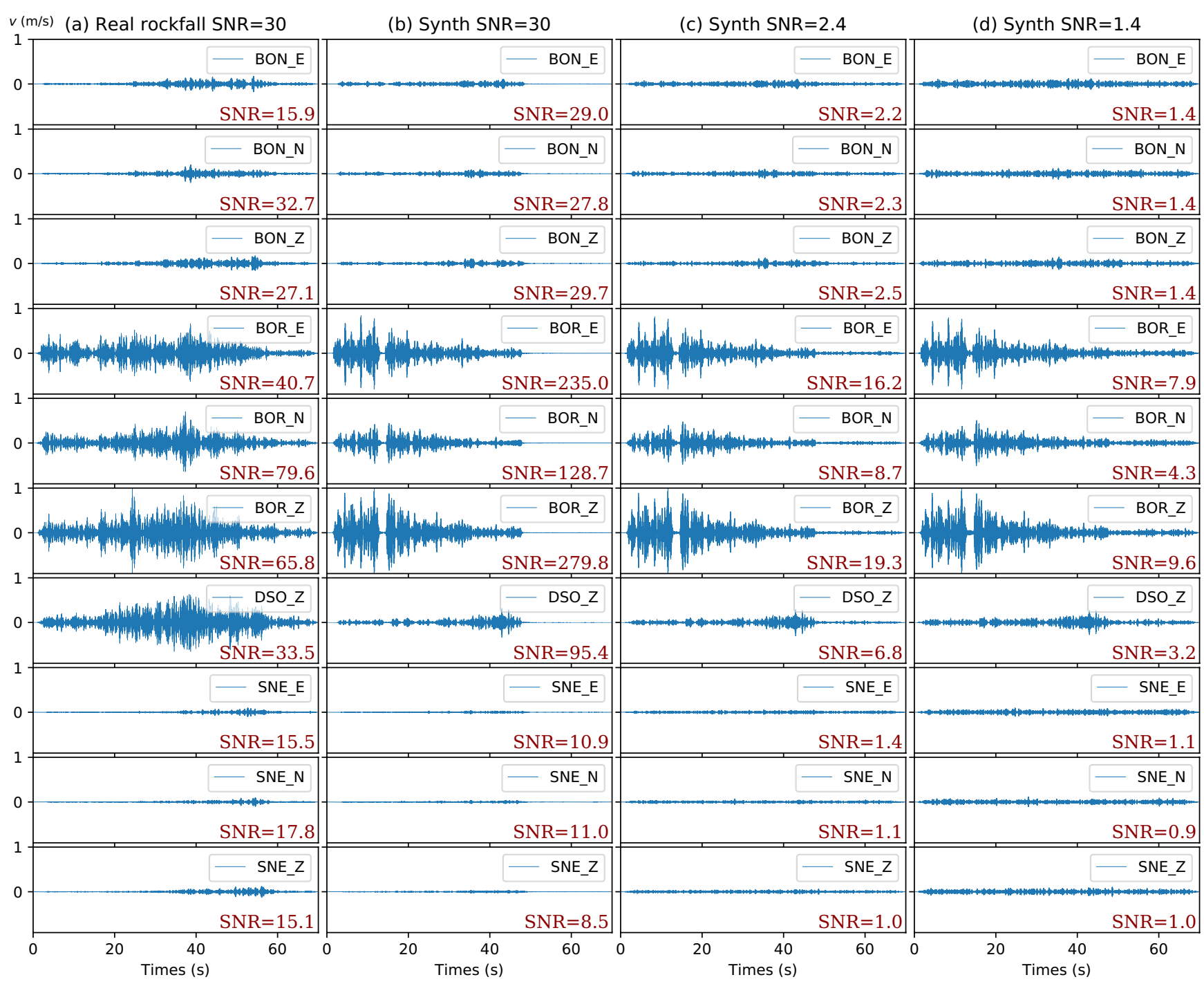

Figure A2. Comparison of signal-to-noise ratios (SNR) for real and synthetic signals, filtered at 13-17 Hz and with normalized amplitudes. (a) Observed signal at Dolomieu crater generated by rockfall on December 13, 2016, with minimum SNR of 15.1 and median SNR of 30.0, which corresponds to a median noise level of 3.4\%. (b) Synthetic signal from the test in Section 5.3, contaminated with a median noise level of 3.4\% (i.e., median SNR $\approx 30$ ), similar to the level on the observed rockfall signal. (c) Synthetic signal contaminated with a median noise level of 41.5\% (i.e., median SNR $\approx 2.4$ ), 12 times higher than the noise level on the observed rockfall signal. SNR values are close to 1 at station SNE, hiding the signals almost entirely. (d) Synthetic signal contaminated with a median noise level of $71.0 \%$ (i.e., median SNR $\approx 1.4$ ), 21 times higher than the level on the observed rockfall signal. SNR values are close to 1 at both station BON and SNE, hiding the signals almost entirely.

\section{Data Availability Statement}

The seismic data were acquired by the Volcanological and Seismological Observatory of Piton de la Fournaise (OVPF)/Institut de Physique du Globe de Paris (IPGP) via the VOLOBSIS Portal: http://volobsis.ipgp. fr/query.php. Camera data are stored in http://doi.org/10.5281/zenodo.4031816. Data from the simulations are available from http://doi.org/10.5281/zenodo.3949826. Numerical computations were partly performed at S-CAPAD (Service de calcul parallèle et de traitement de données en sciences de la Terre), IPGP, France, as well as at CCIPL (Centre de Calcul Intensif des Pays de la Loire), Université de Nantes, France. 


\section{Acknowledgments}

The authors are very grateful to Emma Suriñach and two anonymous reviewers for their critical and constructive remarks which contributed to improve the quality of the present study. The authors want to thank the whole team at the OVPF observatory that provided the excellent field data used in this study. The authors thank the whole team at the OVPF that provided the excellent field data for this study. This work was funded by ERC Contract No. ERC-CG2013-PE10-617472 SLIDEQUAKES.

\section{References}

Aki, K., \& Richards, P. G. (2002). Quantitative seismology (2nd ed., p. 704). University Science Books. Retrieved from https://ui.adsabs. harvard.edu/abs/2002quse.book\ldots\enleadertwodotsA/abstract

Allstadt, K. (2013). Extracting source characteristics and dynamics of the August 2010 Mount Meager landslide from broadband seismograms. Journal of Geophysical Research: Earth Surface, 118, 1472-1490. http://doi.wiley.com/10.1002/jgrf.20110

Allstadt, K. E., Matoza, R. S., Lockhart, A. B., Moran, S. C., Caplan-Auerbach, J., Haney, M. M., et al. (2018). Seismic and acoustic signatures of surficial mass movements at volcanoes. Journal of Volcanology and Geothermal Research, 364, 76-106. https://doi.org/10.1016/j. jvolgeores.2018.09.007

Almendros, J., Chouet, B., Dawson, P., \& Huber, C. (2002). Mapping the sources of the seismic wave field at Kilauea volcano, Hawaii, using data recorded on multiple seismic Antennas. Bulletin of the Seismological Society of America, 92(6), 2333-2351. https://doi. org/10.1785/0120020037

Battaglia, J., \& Aki, K. (2003). Location of seismic events and eruptive fissures on the Piton de la Fournaise volcano using seismic amplitudes. Journal of Geophysical Research, 108(B8), 2364. http://doi.wiley.com/10.1029/2002JB002193

Battaglia, J., Aki, K., \& Staudacher, T. (2005). Location of tremor sources and estimation of lava output using tremor source amplitude on the Piton de la Fournaise volcano: 2. Estimation of lava output. Journal of Volcanology and Geothermal Research, 147(3-4), 291-308. https://doi.org/10.1016/j.jvolgeores.2005.04.006

Bottelin, P., Jongmans, D., Daudon, D., Mathy, A., Helmstetter, A., Bonilla-Sierra, V., et al. (2014). Seismic and mechanical studies of the artificially triggered rockfall at Mount Néron (French Alps, December 2011). Natural Hazards and Earth System Sciences, 14(12), 3175-3193. https://doi.org/10.5194/nhess-14-3175-2014

Burtin, A., Bollinger, L., Cattin, R., Vergne, J., \& Nábělek, J. L. (2009). Spatiotemporal sequence of Himalayan debris flow from analysis of high-frequency seismic noise. Journal of Geophysical Research, 114(4), F04009. http://doi.wiley.com/10.1029/2008JF001198

Burtin, A., Hovius, N., Milodowski, D. T., Chen, Y.-G., Wu, Y.-M., Lin, C.-W., et al. (2013). Continuous catchment-scale monitoring of geomorphic processes with a 2-D seismological array. Journal of Geophysical Research: Earth Surface, 118, 1956-1974. http://doi.wiley. com/10.1002/jgrf.20137

Chaljub, E., Komatitsch, D., Vilotte, J.-P., Capdeville, Y., Valette, B., \& Festa, G. (2007). Spectral-element analysis in seismology. Advances in Geophysics, 48(06), 365-419. https://doi.org/10.1016/S0065-2687(06)48007-9

Coviello, V., Capra, L., Vázquez, R., \& Márquez-Ramírez, V. H. (2018). Seismic characterization of hyperconcentrated flows in a volcanic environment. Earth Surface Processes and Landforms, 43(10), 2219-2231. http://doi.wiley.com/10.1002/esp.4387

Dammeier, F., Moore, J. R., Hammer, C., Haslinger, F., \& Loew, S. (2016). Automatic detection of alpine rockslides in continuous seismic data using hidden Markov models. Journal of Geophysical Research: Earth Surface, 121, 351-371. http://doi.wiley.com/10.1002/2015JF003647

Derrien, A., Villeneuve, N., Peltier, A., \& Michon, L. (2019). Multi-temporal airborne structure-from-motion on caldera rim: Hazard, visitor exposure and origins of instabilities at Piton de la Fournaise. Progress in Physical Geography: Earth and Environment, 43(2), 193-214. https://doi.org/10.1177/0309133318808201

Dietze, M., Mohadjer, S., Turowski, J. M., Ehlers, T. A., \& Hovius, N. (2017). Seismic monitoring of small alpine rockfalls - validity, precision and limitations. Earth Surface Dynamics, 5(4), 653-668. https://doi.org/10.5194/esurf-5-653-2017

Duputel, Z., Lengliné, O., \& Ferrazzini, V. (2019). Constraining spatiotemporal characteristics of magma migration at Piton de la Fournaise volcano from pre-eruptive seismicity. Geophysical Research Letters, 46, 119-127. https://doi.org/10.1029/2018GL080895

Durand, V., Mangeney, A., Haas, F., Jia, X., Bonilla, F., Peltier, A., et al. (2018). On the link between external forcings and slope instabilities in the Piton de la Fournaise Summit crater, Reunion Island. Journal of Geophysical Research: Earth Surface, 123, 2422-2442. http://doi. wiley.com/10.1029/2017JF004507

Ebeling, C. W., \& Stein, S. (2011). Seismological identification and characterization of a large hurricane. Bulletin of the Seismological Society of America, 101(1), 399-403. https://doi.org/10.1785/0120100175

Favreau, P., Mangeney, A., Lucas, A., Crosta, G., \& Bouchut, F. (2010). Numerical modeling of landquakes. Geophysical Research Letters, 37(15), 1-5. http://doi.wiley.com/10.1029/2010GL043512

Festa, G., \& Vilotte, J.-P. (2005). The Newmark scheme as velocity-stress time-staggering: An efficient PML implementation for spectral element simulations of elastodynamics. Geophysical Journal International, 161(3), 789-812. https://academic.oup.com/gji/article-lookup/ doi/10.1111/j.1365-246X.2005.02601.X

Fuchs, F., Lenhardt, W., \& Bokelmann, G. (2018). Seismic detection of rockslides at regional scale: Examples from the Eastern Alps and feasibility of kurtosis-based event location. Earth Surface Dynamics, 6(4), 955-970. https://doi.org/10.5194/esurf-6-955-2018

Geli, L., Bard, P. Y., \& Jullien, B. (1988). The effect of topography on earthquake ground motion: A review and new results. Bulletin of the Seismological Society of America, 78(1), 42-63. https://doi.org/10.1016/0148-9062(88)90024-1

Gimbert, F., Tsai, V. C., \& Lamb, M. P. (2014). A physical model for seismic noise generation by turbulent flow in rivers. Journal of Geophysical Research: Earth Surface, 119, 2209-2238. http://doi.wiley.com/10.1002/2014JF003201

Gracchi, T., Lotti, A., Saccorotti, G., Lombardi, L., Nocentini, M., Mugnai, F., et al. (2017). A method for locating rockfall impacts using signals recorded by a microseismic network. Geoenviron Disasters, 4(1). https://doi.org/10.1186/s40677-017-0091-z

Helmstetter, A., \& Garambois, S. (2010). Seismic monitoring of Schilienne rockslide (French Alps): Analysis of seismic signals and their correlation with rainfalls. Journal of Geophysical Research, 115(3), F03016. http://doi.wiley.com/10.1029/2009JF001532

Hibert, C., Mangeney, A., Grandjean, G., Baillard, C., Rivet, D., Shapiro, N. M., et al. (2014). Automated identification, location, and volume estimation of rockfalls at Piton de la Fournaise volcano. Journal of Geophysical Research: Earth Surface, 119, 1082-1105. http://doi.wiley. com/10.1002/2013JF002970

Hibert, C., Mangeney, A., Grandjean, G., Peltier, A., DiMuro, A., Shapiro, N. M., et al. (2017). Spatio-temporal evolution of rockfall activity from 2007 to 2011 at the Piton de la Fournaise volcano inferred from seismic data. Journal of Volcanology and Geothermal Research, 333-334, 36-52. https://doi.org/10.1016/j.jvolgeores.2017.01.007

Hibert, C., Mangeney, A., Grandjean, G., \& Shapiro, N. M. (2011). Slope instabilities in Dolomieu crater, Réunion Island: From seismic signals to rockfall characteristics. Journal of Geophysical Research, 116(4), 1-18. http://doi.wiley.com/10.1029/2011JF002038

Hibert, C., Provost, F., Malet, J.-P., Maggi, A., Stumpf, A., \& Ferrazzini, V. (2017). Automatic identification of rockfalls and volcano-tectonic earthquakes at the Piton de la Fournaise volcano using a Random Forest algorithm. Journal of Volcanology and Geothermal Research, 340, 130-142. http://dx.doi.org/10.1016/j.jvolgeores.2017.04.015

Kijko, A. (1977). An algorithm for the optimum distribution of a regional seismic network - II. An analysis of the accuracy of location of local earthquakes depending on the number of seismic stations. Pure and Applied Geophysics (PAGEOPH), 115(4), 1011-1021. https:// doi.org/10.1007/BF00881223 
Kluyver, T., Ragan-Kelley, B., Pérez, F., Granger, B., Bussonnier, M., Frederic, J., et al. (2016). Jupyter notebooks-A publishing format for reproducible computational workflows. In Positioning and power in academic publishing: Players, agents and agendas - Proceedings of the 20th International Conference on Electronic Publishing, elpub 2016 (pp. 87-90). IOS Press. https://doi.org/10.3233/978-1-61499-649-1-87

Komatitsch, D., \& Vilotte, J. P. (1998). The spectral element method: An efficient tool to simulate the seismic response of 2D and 3D geological structures. Bulletin of the Seismological Society of America, 88(2), 368-392.

Konno, K., \& Ohmachi, T. (1998). Ground-motion characteristics estimated from spectral ratio between horizontal and vertical components of microtremor. Bulletin of the Seismological Society of America, 88(1), 228-241.

Kraft, T., Mignan, A., \& Giardini, D. (2013). Optimization of a large-scale microseismic monitoring network in northern switzerland. Geophysical Journal International, 195(1), 474-490. https://doi.org/10.1093/gji/ggt225

Kuehnert, J., Mangeney, A., Capdeville, Y., Métaxian, J. P., Bonilla, L. F., Stutzmann, E., et al. (2020). Simulation of topography effects on rockfall-generated seismic signals: Application to Piton de la Fournaise volcano. Journal of Geophysical Research: Solid Earth, 125. https://agupubs.onlinelibrary.wiley.com/doi/full/10.1029/2020JB019874

Kuehnert, J., Mangeney, A., Capdeville, Y., Vilotte, J.-P., Stutzmann, E., \& Chaljub, E. (2019). Rockfall localization routine. Zenodo. https:// doi.org/10.5281/zenodo.3550192

Kumagai, H., Nakano, M., Maeda, T., Yepes, H., Palacios, P., Ruiz, M., et al. (2010). Broadband seismic monitoring of active volcanoes using deterministic and stochastic approaches. Journal of Geophysical Research, 115(8). https://agupubs.onlinelibrary.wiley.com/doi/ full/10.1029/2009JB006889

Kumagai, H., Palacios, P., Maeda, T., Castillo, D. B., \& Nakano, M. (2009). Seismic tracking of lahars using tremor signals. Journal of Volcanology and Geothermal Research, 183(1-2), 112-121. https://doi.org/10.1016/j.jvolgeores.2009.03.010

Kumagai, H., Saito, T., O'Brien, G., \& Yamashina, T. (2011). Characterization of scattered seismic wavefields simulated in heterogeneous media with topography. Journal of Geophysical Research, 116(3), 1-13. https://doi.org/10.1029/2010JB007718

Lacroix, P., \& Helmstetter, A. (2011). Location of seismic signals associated with microearthquakes and rockfalls on the Sechilienne Landslide, French Alps. Bulletin of the Seismological Society of America, 101(1), 341-353. https://doi.org/10.1785/0120100110

Larose, E., Carrière, S., Voisin, C., Bottelin, P., Baillet, L., Guéguen, P., et al. (2015). Environmental seismology: What can we learn on earth surface processes with ambient noise? Journal of Applied Geophysics, 116, 62-74. http://dx.doi.org/10.1016/j.jappgeo.2015.02.001

Lee, E.-J., Liao, W.-Y., Lin, G.-W., Chen, P., Mu, D., \& Lin, C.-W. (2019). Toward automated real-time detection and location of large-scale landslides through seismic waveform back projection. Geofluids, 2019, 1-14. https://doi.org/10.1155/2019/1426019

Lee, S.-J., Chan, Y.-C., Komatitsch, D., Huang, B.-S., \& Tromp, J. (2009). Effects of realistic surface topography on seismic ground motion in the Yangminshan region of Taiwan based upon the spectral-element method and LiDAR DTM. Bulletin of the Seismological Society of America, 99(2A), 681-693. https://doi.org/10.1785/0120080264

Lengliné, O., Duputel, Z., \& Ferrazzini, V. (2016). Uncovering the hidden signature of a magmatic recharge at Piton de la Fournaise volcano using small earthquakes. Geophysical Research Letters, 43, 4255-4262. https://doi.org/10.1002/2016GL068383

Leprettre, B., Martin, N., Glangeaud, F., \& Navarre, J.-P. (1998). Three-component signal recognition using time, time-frequency, and polarization information-application to seismic detection of avalanches. IEEE Transactions on Signal Processing, 46(1), 83-102. https:// doi.org/10.1109/78.651183

Lesage, P., Heap, M. J., \& Kushnir, A. (2018). A generic model for the shallow velocity structure of volcanoes. Journal of Volcanology and Geothermal Research, 356, 114-126. https://doi.org/10.1016/j.jvolgeores.2018.03.003

Levy, C., Mangeney, A., Bonilla, F., Hibert, C., Calder, E. S., \& Smith, P. J. (2015). Friction weakening in granular flows deduced from seismic records at the Soufrière Hills Volcano, Montserrat. Journal of Geophysical Research: Solid Earth, 120, 7536-7557. https://doi. org/10.1002/2015JB012151

Li, L., Tan, J., Schwarz, B., Staněk, F., Poiata, N., Shi, P., et al. (2020). Recent advances and challenges of waveform-based seismic location methods at multiple scales. Reviews of Geophysics, 58(1). Blackwell Publishing Ltd. https://agupubs.onlinelibrary.wiley.com/doi/ full/10.1029/2019RG000667

Maggi, A., Ferrazzini, V., Hibert, C., Beauducel, F., Boissier, P., \& Amemoutou, A. (2017). Implementation of a multistation approach for automated event classification at Piton de la Fournaise volcano. Seismological Research Letters, 88(3), 878-891. http://srl.geoscienceworld.org/lookup/doi/10.1785/0220160189

Maufroy, E., Cruz-Atienza, V. M., Cotton, F., \& Gaffet, S. (2015). Frequency-scaled curvature as a proxy for topographic site-effect amplification and ground-motion variability. Bulletin of the Seismological Society of America, 105(1), 354-367. https://doi.org/10.1785/0120140089

Métaxian, J. P., O'Brien, G. S., Bean, C. J., Valette, B., \& Mora, M. (2009). Locating volcano-seismic signals in the presence of rough topography: Wave simulations on Arenal volcano, Costa Rica. Geophysical Journal International, 179(3), 1547-1557. https://academic.oup. com/gji/article-lookup/doi/10.1111/j.1365-246X.2009.04364.x

Michon, L., Staudacher, T., Ferrazzini, V., Bachèlery, P., \& Marti, J. (2007). April 2007 collapse of Piton de la Fournaise: A new example of caldera formation. Geophysical Research Letters, 34(21), L21301. http://doi.wiley.com/10.1029/2007GL031248

MMesch. (2016). MMesch/cmap_builder: colormap2d-v0.5. Zenodo. Retrieved from https://zenodo.org/record/192611

Morioka, H., Kumagai, H., \& Maeda, T. (2017). Theoretical basis of the amplitude source location method for volcano-seismic signals Journal of Geophysical Research: Solid Earth, 122, 6538-6551. http://doi.wiley.com/10.1002/2017JB013997

Norris, R. D. (1994). Seismicity of rockfalls and avalanches at three Cascade Range volcanoes: Implications for seismic detection of hazardous mass movements. Bulletin of the Seismological Society of America, 84(6), 1925-1939. https://doi.org/10.1016/0148-9062(95)99022-p

O'Brien, G. S., \& Bean, C. J. (2009). Volcano topography, structure and intrinsic attenuation: Their relative influences on a simulated 3D visco-elastic wavefield. Journal of Volcanology and Geothermal Research, 183(1-2), 122-136. http://dx.doi.org/10.1016/j. jvolgeores.2009.03.004

Pérez-Guillén, C., Tsunematsu, K., Nishimura, K., \& Issler, D. (2019). Seismic location and tracking of snow avalanches and slush flows on Mt. Fuji, Japan. Earth Surface Dynamics, 7(4), 989-1007. https://doi.org/10.5194/esurf-7-989-2019

Podolskiy, E. A., \& Walter, F. (2016). Cryoseismology. Reviews of Geophysics, 54(4), 708-758. http://doi.wiley.com/10.1002/2016RG000526

Provost, F., Hibert, C., \& Malet, J.-P. (2017). Automatic classification of endogenous landslide seismicity using the Random Forest supervised classifier. Geophysical Research Letters, 44, 113-120. http://doi.wiley.com/10.1002/2016GL070709

Rabinowitz, N., \& Steinberg, D. M. (1990). Optimal configuration of a seismographic network: A statistical approach. Bulletin of the Seismological Society of America, 80(1), 187-196.

Ripperger, J., Igel, H., \& Wasserman, J. (2003). Seismic wave simulation in the presence of real volcano topography. Journal of Volcanology and Geothermal Research, 128(1-3), 31-44. https://doi.org/10.1016/S0377-0273(03)00245-2 
Sergeant, A., Mangeney, A., Stutzmann, E., Montagner, J. P., Walter, F., Moretti, L., \& Castelnau, O. (2016). Complex force history of a calving-generated glacial earthquake derived from broadband seismic inversion. Geophysical Research Letters, 43, 1055-1065. https:// doi.org/10.1002/2015GL066785

Sergeant, A., Mangeney, A., Yastrebov, V. A., Walter, F., Montagner, J.-P., Castelnau, O., et al. (2019). Monitoring Greenland ice sheet buoyancy-driven calving discharge using glacial earthquakes. Annals of Glaciology, 60(79), 75-95. https://doi.org/10.1017/aog.2019.7

Stutzmann, E., Ardhuin, F., Schimmel, M., Mangeney, A., \& Patau, G. (2012). Modeling long-term seismic noise in various environments. Geophysical Journal International, 191(2), 707-722. https://academic.oup.com/gii/article-lookup/doi/10.1111/j.1365-246X.2012.05638.x

Suriñach, E., Furdada, G., Sabot, F., Biesca, B., \& Vilaplana, J. M. (2001). On the characterization of seismic signals generated by snow avalanches for monitoring purposes. Annals of Glaciology, 32, 268-274. https://doi.org/10.3189/172756401781819634

Suriñach, E., Sabot, F., Furdada, G., \& Vilaplana, J. M. (2000). Study of seismic signals of artificially released snow avalanches for monitoring purposes. Physics and Chemistry of the Earth - Part B: Hydrology, Oceans and Atmosphere, 25(9), 721-727. https://doi.org/10.1016/ S1464-1909(00)00092-7

Suriñach, E., Vilajosana, I., Khazaradze, G., Biescas, B., Furdada, G., \& Vilaplana, J. M. (2005). Seismic detection and characterization of landslides and other mass movements. Natural Hazards and Earth System Sciences, 5(6), 791-798. https://doi.org/10.5194/ nhess-5-791-2005

Taisne, B., Brenguier, F., Shapiro, N. M., \& Ferrazzini, V. (2011). Imaging the dynamics of magma propagation using radiated seismic intensity. Geophysical Research Letters, 38(4). http://doi.wiley.com/10.1029/2010GL046068

Takemura, S., Furumura, T., \& Saito, T. (2009). Distortion of the apparent S-wave radiation pattern in the high-frequency wavefield: Tottori-Ken Seibu, Japan, earthquake of 2000. Geophysical Journal International, 178(2), 950-961. https://academic.oup.com/gji/ article-lookup/doi/10.1111/j.1365-246X.2009.04210.x

Toledo, T., Jousset, P., Maurer, H., \& Krawczyk, C. (2020). Optimized experimental network design for earthquake location problems: Applications to geothermal and volcanic field seismic networks. Journal of Volcanology and Geothermal Research, 391, 106433. https:// doi.org/10.1016/j.jvolgeores.2018.08.011

Tsai, V. C., Rice, J. R., \& Fahnestock, M. (2008). Possible mechanisms for glacial earthquakes. Journal of Geophysical Research, 113(3), F03014. http://doi.wiley.com/10.1029/2007JF000944

Vázquez, R., Suriñach, E., Capra, L., Arámbula-Mendoza, R., \& Reyes-Dávila, G. (2016). Seismic characterisation of lahars at Volcán de Colima, Mexico. Bulletin of Volcanology, 78(2), 1-14. https://link.springer.com/article/10.1007/s00445-016-1004-9

Vilajosana, I., Suriñach, E., Abellán, A., Khazaradze, G., Garcia, D., \& Llosa, J. (2008). Rockfall induced seismic signals: Case study in Montserrat, Catalonia. Natural Hazards and Earth System Science, 8(4), 805-812.Retrieved from https://www.nat-hazards-earth-systsci.net/8/805/2008/

Vouillamoz, N., Rothmund, S., \& Joswig, M. (2018). Characterizing the complexity of microseismic signals at slow-moving clay-rich debris slides: The Super-Sauze (southeastern France) and Pechgraben (Upper Austria) case studies. Earth Surface Dynamics, 6(2), 525-550. https://doi.org/10.5194/esurf-6-525-2018

Walsh, B., Jolly, A. D., \& Procter, J. (2017). Calibrating the amplitude source location (ASL) method by using active seismic sources: An example from Te Maari volcano, Tongariro National Park, New Zealand. Geophysical Research Letters, 44, 3591-3599. http://doi.wiley. com/10.1002/2017GL073000

Walsh, B., Procter, J., \& Jolly, A. (2020). Improving the Amplitude Source Location (ASL) method using multicomponent seismic data: An assessment with active source seismic data. Bulletin of the Seismological Society of America, 110(1), 250-269. https://doi. org/10.1785/0120190063

Walter, F., Burtin, A., McArdell, B. W., Hovius, N., Weder, B., \& Turowski, J. M. (2017). Testing seismic amplitude source location for fast debris-flow detection at Illgraben, Switzerland. Natural Hazards and Earth System Sciences, 17(6), 939-955.Retrieved from https://www. nat-hazards-earth-syst-sci.net/17/939/2017/

Yamada, M., Matsushi, Y., Chigira, M., \& Mori, J. (2012). Seismic recordings of landslides caused by Typhoon Talas (2011), Japan. Geophysical Research Letters, 39(13). http://doi.wiley.com/10.1029/2012GL052174

Zobin, V. M. (2012). 13 - seismic signals associated with pyroclastic flows, rockfalls, and lahars. In V. M. Zobin (Ed.), Introduction to volcanic seismology (2nd ed. pp. 261-293). Oxford: Elsevier. Retrieved from http://www.sciencedirect.com/science/article/pii/ B978044456375000013X

Zobin, V. M., Plascencia, I., Reyes, G., \& Navarro, C. (2009). The characteristics of seismic signals produced by lahars and pyroclastic flows: Volcán de Colima, México. Journal of Volcanology and Geothermal Research, 179(1-2), 157-167. https://doi.org/10.1016/j. jvolgeores.2008.11.001 